\title{
Lagrangian observations in the Intermediate Western Boundary Current of the South Atlantic
}

\author{
Jean-François Legeais ${ }^{1}$, Michel Ollitrault ${ }^{*}$, Michel Arhan
}

\author{
Laboratoire de Physique des Océans, CNRS/IFREMER/IRD/UBO, IFREMER/Centre de Brest, B.P. 70, 29280 \\ Plouzané, France \\ ${ }^{1}$ Present address: Collecte Localisation Satellites (CLS), Space Oceanography Division, 8-10 rue Hermès, 31520 \\ Ramonville Saint-Agne, France. \\ *: Corresponding author : Michel Ollitrault, email address : $\underline{\text { michel.ollitrault@ifremer.fr }}$
}

\begin{abstract}
:
Subsurface float measurements at $800 \mathrm{~m}$ depth carried out from 1994 to 2003 in the Brazil Basin are used to characterise the equatorward Intermediate Western Boundary Current (IWBC) and its connections to the ocean interior. Transversally, the boundary flow is less than $100 \mathrm{~km}$ wide, and most intense at $10-20 \mathrm{~km}$ from the $800 \mathrm{~m}$ isobath. Its average velocities range from $\sim 0.1 \mathrm{~ms}^{-1}$ to $0.3 \mathrm{~ms}^{-1}$ depending on latitude, with individual daily values as high as $0.7 \mathrm{~ms}^{-1}$. The flow meridional extent exhibits 3 contrasted domains: (i) from $27^{\circ} \mathrm{S}$ to the Vitoria-Trindade Ridge at $20^{\circ} 30^{\prime} \mathrm{S}$, the boundary flow intensifies northward along a relatively smooth topography. A counter current adjacent to it on its seaward side feeds it with intermediate water from the northern limb of the subtropical gyre. (ii) At latitudes $20-15^{\circ} \mathrm{S}$ characterised by a very irregular topography, the IWBC becomes weaker with even no real proof of its presence at $18-15^{\circ} \mathrm{S}$. An intense mesoscale variability prevails there, which apparently takes over from the boundary flow to ensure the northward transport of water to $15^{\circ} \mathrm{S}$, where the IWBC re-forms. (iii) North of this latitude, the boundary flow increases again to $\sim 10^{\circ} \mathrm{S}$ along smooth isobaths, then decreases when encountering a rougher topography and the zonal jets of the equatorial current system. A counter current present from $\sim 5^{\circ} \mathrm{S}$ to $14^{\circ} \mathrm{S}$, partly fed from the boundary flow, contributes to its drainage. The IWBC shows two main input locations, at $27-23^{\circ} \mathrm{S}$ and $15-12^{\circ} \mathrm{S}$ in the southern parts of the two latitudinal domains of smooth topography where the northward current increases. Output locations coincide with major capes in the continental slope geometry, at $20^{\circ} \mathrm{S}$ and $18^{\circ} \mathrm{S}$ (the southeastern and northeastern corners of the Abrolhos Bank), at $8^{\circ} \mathrm{S}$ near the Recife Plateau, and at $5^{\circ} \mathrm{S}$ near Cape São Roque.
\end{abstract}

Keywords: Brazil basin ; Intermediate water ; Western boundary current 


\section{I - Introduction}

The World Ocean Circulation Experiment (WOCE) in the 1990's induced several studies of the circulation of the Antarctic Intermediate Water (AAIW) in the South Atlantic, which had as a common and ultimate objective a better understanding of the way this water mass crosses the ocean basin northward, and contributes to the warm limb of the Atlantic meridional circulation. The works of Reid (1989), Warner and Weiss (1992), and Suga and Talley (1995), all resting on hydrographic and tracer data, revealed a mostly wind-driven AAIW circulation structured into a subtropical gyre south of $\sim 20^{\circ} \mathrm{S}$, a tropical gyre, and a system of zonal equatorial currents. Several subsurface float experiments carried out under the auspices of WOCE $\left(\mathrm{DBE}^{1}\right)$, or as follows-on of this program $\left(\mathrm{KAPEX}^{2}\right)$, provided direct confirmations of most aspects of the AAIW circulation. Boebel et al. (1997), combining the first available float data to hydrographic and current meter data, described the bifurcation of the northern westward limb of the AAIW subtropical gyre near $28^{\circ} \mathrm{S}$ at the Brazilian continental slope, which they called the "Santos bifurcation". They underlined that this location is where a northward Intermediate Western Boundary Current (IWBC) originates, as the boundary flow farther south at $\sim 40^{\circ} \mathrm{S}-30^{\circ} \mathrm{S}$ is exclusively southward. Also using float data, Boebel et al. (1999a) and Boebel et al. (2003) discussed the role of mesoscale features in the spreading of AAIW in the western South Atlantic basin and the eastern part of the subtropical gyre, respectively. Schmid et al. (2000) and Nuñez-Riboni et al. (2005) quantified the AAIW subtropical gyre volume transports, and the inputs/outputs at the gyre western and eastern sides. In the equatorial region, Ollitrault et al. (2006) provided an accurate description of the equatorial zonal intermediate currents, including their seasonal variations.

Boebel et al. (1999b) summarized the results of most of the above-quoted studies in a schematic diagram of the main flow patterns at intermediate depths in the western South Atlantic. Although in that diagram the IWBC appears as an essential feature connecting the subtropical gyre to the equatorial jets, it looks like this current did not receive as much attention as would be justified from its role in the northward transfer of AAIW. Apart from a few subsurface float trajectories that revealed it in the work of Boebel et al. (1999b), our knowledge of it mainly rests on local Eulerian measurements at a few different places along its course. The first of these were punctual Pegasus velocity profiles at $\sim 23^{\circ} \mathrm{S}$ reported by Evans and Signorini (1985), which revealed alongslope equatorward velocity maxima up to

\footnotetext{
${ }^{1}$ DBE : Deep Basin Experiment.

${ }^{2}$ KAPEX : Cape of Goodhope Experiments (Richardson et al., 2003).
} 
$0.35 \mathrm{~ms}^{-1}$ at $800 \mathrm{~m}$ depth. Müller et al. (1998) reported measurements of two year duration at $28^{\circ} \mathrm{S}$ and one year at $23^{\circ} \mathrm{S}$ and $20^{\circ} \mathrm{S}$, the latter being located in the western channels of the Vitoria-Trindade Ridge (hereafter VTR; Fig.1a). While the former, located just south of the Santos bifurcation, produced poleward averaged velocities at the intermediate levels, the latter two showed equatorward mean flows of $0.12 \mathrm{~ms}^{-1}$ (at $23^{\circ} \mathrm{S}$ ) and $0.21 \mathrm{~ms}^{-1}$ (at $20^{\circ} \mathrm{S}$ ). In the same area $\left(22^{\circ} 42^{\prime} \mathrm{S}\right)$ Silveira et al. (2008) reports a 5-month average equatorward velocity of $0.22 \mathrm{~ms}^{-1}$ at $900 \mathrm{~m}$ depth in the IWBC. At $18^{\circ} \mathrm{S}$, however, other near-slope18-month duration measurements at $900 \mathrm{~m}$ by Weatherly et al. (2000) did not reveal any IWBC, the flow being highly variable. Still farther north at $11^{\circ} \mathrm{S}$ and $5^{\circ} \mathrm{S}$, a well-defined IWBC was found again in current meter and Acoustic Doppler Current Profiler (ADCP) data by Schott et al. (2005), with mean velocities of $0.15-0.30 \mathrm{~ms}^{-1}$. At these latitudes, the IWBC is overridden by a stronger flow of South Atlantic Central Water in the same direction, the two flows constituting the so-called North Brazil Undercurrent (NBUC; Silveira et al., 1994; Stramma et al., 1995).

A comprehensive view of the South Atlantic western boundary current system, including information on the AAIW component, may be found in Wienders et al. (2000), who realized a hydrographic inversion of a WOCE section parallel to the coast at $\sim 600 \mathrm{~km}$ from it, and extending from $50^{\circ} \mathrm{S}$ to $10^{\circ} \mathrm{N}$. Their results, when interpreted in terms of alongshore transports (between the coast and the hydrographic line), provide the approximate meridional structure of the western boundary flow for each water mass. The IWBC is seen to originate at $28^{\circ} \mathrm{S}$ and to increase, on average, toward the equator, yet with local reversed gradients notably at $20^{\circ} \mathrm{S}-15^{\circ} \mathrm{S}$. Vertically, and between $28^{\circ} \mathrm{S}$ and $\sim 13^{\circ} \mathrm{S}$, it separates the southward flows associated with the Brazil Current (above), and with the Deep Western Boundary Current (below). North of $\sim 13^{\circ} \mathrm{S}$, the overriding flow is itself northward, as just mentioned. Between $28^{\circ} \mathrm{S}$ and $\sim 40^{\circ} \mathrm{S}$, the AAIW boundary flow is southward and joins in with the overand underlying currents in a thick poleward boundary flow extending vertically from the surface down to the base of the Deep Waters at about $3000 \mathrm{~m}$ depth. Because the IWBC is much narrower than $600 \mathrm{~km}$, however, its transport estimates in Wienders et al. (2000) might be poor at latitudes where current re-circulations exist inshore of the hydrographic line.

From the above, our present knowledge of the IWBC rests either on local Eulerian velocity measurements, which at a few latitudes provide an accurate transverse description of the current, or on hydrographic data which, though providing a satisfactory description of the 
alongshore current structure, are less accurate as for velocity and transport estimates. In this article, we use subsurface float data from the French DBE/SAMBA experiment that repeatedly sampled the IWBC between 1994 and 2003, for a characterization of both the alongslope and transverse structures of the current. Owing to their 3-year average life time, many floats from that experiment, initially launched in the interior of the Brazil Basin, drifted to the vicinity of the South American continental slope, and were entrained in the IWBC (Fig.1b). Section 2 gives more information on the data set, and briefly presents the large-scale and mesoscale IWBC environments as given by the floats. Section 3 describes the method used to select the parts of the float trajectories that sampled the IWBC. The meridional and transverse structures of the boundary current are studied in Sections 4 and 5, respectively, and the latter also discusses the associated transports and the counter-currents present at some latitudes. Section 6 focuses on two regions with particularly high mesoscale activity, the Santos Plateau and the area north of the Vitoria-Trindade seamounts. In Section 7 are examined the preferential locations of exchange between the IWBC and the ocean interior, and the float-inferred residence times over the whole extent of the current and in its subsections.

\section{II - The data. The IWBC large scale and meso-scale environments.}

a) The float data

The subsurface floats used during the SAMBA experiment are acoustically tracked, multi-cycle MARVOR floats (Ollitrault et al., 1995; Ollitrault, 1999). They are designed to perform successive measurement cycles during which they sink to a prescribed pressure (here 800 dbar), drift at that pressure during 2 or 3 months (the cycle durations retained for SAMBA), then return to the surface where they remain for 2 or 3 days (respectively) to transmit the data via the satellite ARGOS system, before starting a new cycle. Such cycles are repeated during 3 to 5 years. The floats are RAFOS-type instruments located once a day using the signals received from an array $^{3}$ of acoustic sources (Rossby et al., 1986). Pressure and temperature measurements are also realized once a day. As the floats are isobaric, they may cross sloping isopycnal surfaces. A total of 100 MARVOR floats were launched between 1994 and 1997 in the framework of SAMBA, which provided about 300 years of data. The tracking of the last float was interrupted at the end of 2003. About one tenth of this data set

\footnotetext{
${ }^{3}$ The sound sources array was maintained over the years through coopération between WHOI, IFM-GEOMAR and IFREMER.
} 
(32 float-years from 1994 to 1996) was already used in the study of Boebel et al. (1999b), where they provided the sampling of the IWBC in the float-inferred schematics of the western South Atlantic intermediate circulation proposed by the authors. That study did not include any discussion of the boundary flow structure, however, which a much larger data quantity now makes possible.

The raw time series of float latitudes and longitudes were passed through a Lanczos filter with cut-off period of 3 days and half width of 10 days. Cubic spline functions were then fitted to the same time series, in order to estimate the eastward and northward float velocity components (Ollitrault et al., 1995). The trajectories thus obtained provide a good coverage of the western South Atlantic, from $\sim 30^{\circ} \mathrm{S}$ to $\sim 5^{\circ} \mathrm{N}$, particularly of the region close to the western border (Fig.1b).

The tracking of the SAMBA floats for a 10-year period (1994-2003) and over a large portion of the Equatorial and Western south Atlantic, required several sound sources (roughly ten at a time) located so that at least two sources should be heard by a float whatever its position. This was not always possible however, close to the continent, because of islands, capes or seamounts preventing the sound from reaching a float drifting there. We managed nevertheless to reconstruct occasionally a few float trajectories, with only one source heard, from geometrical considerations (and a precise bathymetry such as SRTM30+). Besides these difficult cases, most float positions are estimated with a few kilometres error. A few MARVOR floats sank due to valve problems, but most were very stable around 800 dbar: actually $95 \%$ of the daily measured pressures are comprised between 750 and $900 \mathrm{dbar}$.

b) Large scale and meso-scale IWBC environments

The presence of the IWBC along the South American continental slope is illustrated in Figure 2 by the trajectories of 3 floats launched in the ocean interior at $22^{\circ} 30^{\circ} \mathrm{S}, 18^{\circ} \mathrm{S}$, and $5^{\circ} \mathrm{S}$. The southern one rejoins the western boundary after three cycles and drifts in the boundary current until it reaches the VTR at $20^{\circ} 30^{\prime}$ S. It leaves the boundary at this latitude, yet proceeds northward looping along its trajectory, joins briefly the western boundary near $18^{\circ} \mathrm{S}$ but re-enters definitely the IWBC only near $13^{\circ} \mathrm{S}$, staying in it at least to $\sim 2^{\circ} \mathrm{S}$. The two others join the boundary along more contorted paths, then follow the IWBC from $\sim 13^{\circ} \mathrm{S}$ to $\sim 2^{\circ} \mathrm{S}$ for one, and from $\sim 11^{\circ} \mathrm{S}$ to $\sim 5^{\circ} \mathrm{S}$ for the other, the latter being detrained from the IWBC after passing through the atol das Rocas seamounts, east of Fernando do Noronha. 
Prior to focusing on the IWBC, we present in Figure $3 \mathrm{a}$ a reminder of the large scale circulation at intermediate levels, here obtained by averaging the SAMBA daily float velocities in $1^{\circ} \times 1^{\circ}$ boxes, superimposed on the 800 dbar temperature distribution, also measured by the floats. Figure $3 b$ displays the Eddy Kinetic Energy (EKE) also computed in $1^{\circ} \times 1^{\circ}$ boxes. In Figure $3 a$, the meridional temperature variations are the 800 dbar imprints of the isotherms vertical displacements associated with the large scale subtropical gyre (south of $\sim 20^{\circ} \mathrm{S}$ ), tropical gyre (from $20^{\circ} \mathrm{S}$ to $5^{\circ} \mathrm{S}$ ), and equatorial current system. The IWBC itself appears through along-slope northward protrusions of warmer water from the subtropics at $15^{\circ} \mathrm{S}-20^{\circ} \mathrm{S}$, and of colder water from the tropics north of $\sim 10^{\circ} \mathrm{S}$, the latter extending eastward at $\sim 2^{\circ} \mathrm{S}$ along the Southern Intermediate Counter Current (SICC; Schott et al.,1995; Ollitrault et al., 2006). The westward northern limb of the subtropical gyre south of $20^{\circ} \mathrm{S}$ and the system of equatorial zonal jets north of $5^{\circ} \mathrm{S}$ both stand out in the map of averaged float velocities. The former, here observed at $20^{\circ} \mathrm{S}-30^{\circ} \mathrm{S}$, was only partially sampled by the SAMBA floats. Other Lagrangian data sets (Boebel et al., 1997) and indirect velocity estimations (Wienders et al., 2000) showed that the subtropical westward flow at intermediate levels extends southward to $\sim 33^{\circ} \mathrm{S}$. The Santos bifurcation, nevertheless, is quite visible at $27^{\circ} \mathrm{S}-28^{\circ} \mathrm{S}$ in Figure $3 \mathrm{a}$. The tropical domain at $20^{\circ} \mathrm{S}-5^{\circ} \mathrm{S}$ is characterized by weak averaged velocities $\left(O\left(0.01 \mathrm{~ms}^{-1}\right)\right)$ in the ocean interior. In contrast, the IWBC is detected at nearly all latitudes north of $27^{\circ} \mathrm{S}$ by $O\left(0.1 \mathrm{~ms}^{-1}\right)$ alongshore equatorward mean velocities. Adjacent to its seaward side at $6^{\circ} \mathrm{S}-13^{\circ} \mathrm{S}$ is a southward counter current (see also the blue float in Figure 2) that was also found in previous Eulerian measurements (Schott et al., 2005). A similar feature is observed at $22^{\circ} \mathrm{S}-26^{\circ} \mathrm{S}$.

The EKE distribution in Figure $3 b$ exhibits a pronounced contrast between the ocean interior, characterized by values of $10-20 \mathrm{~cm}^{2} \mathrm{~s}^{-2}$, and the western boundary domain where the EKE exceeds $50 \mathrm{~cm}^{2} \mathrm{~s}^{-2}$. Along the boundary, values exceeding $100 \mathrm{~cm}^{2} \mathrm{~s}^{-2}$ reveal an increased variability at three locations: Above the Santos Plateau at $24^{\circ} \mathrm{S}-27^{\circ} \mathrm{S}$, between $21^{\circ} \mathrm{S}$ and $15^{\circ} \mathrm{S}$, where an irregular continental slope and several seamounts might destabilize the boundary flow, and near the Recife Plateau at $8^{\circ} \mathrm{S}-10^{\circ} \mathrm{S}$. Previous Lagrangian measurements (Boebel et al., 1999a) also showed an increase of EKE near the Santos Plateau, yet with maximum values not exceeding $5 \mathrm{Jm}^{-3}\left(50 \mathrm{~cm}^{2} \mathrm{~s}^{-2}\right)$, well below those observed at $25^{\circ} \mathrm{S}-27^{\circ} \mathrm{S}$ in figure $3 \mathrm{~b}$. The coastal intensification visible at $15^{\circ} \mathrm{S}-18^{\circ} \mathrm{S}$ on the same Figure matches results of Weatherly et al. (2000) who, from an Eulerian array of current measurements perpendicular to the continental slope, found EKE average values of $\sim 300 \mathrm{~cm}^{2} \mathrm{~s}^{-2}$ within the 
most inshore breadth of $300 \mathrm{~km}$, strongly contrasting with values of $20-30 \mathrm{~cm}^{2} \mathrm{~s}^{-2}$ farther offshore.

\section{III - Selecting floats in the intermediate boundary currents}

The subsurface float positions that sampled the western boundary currents (the IWBC north of $27^{\circ} \mathrm{S}$ and the Brazil Current at the intermediate level south of $27^{\circ} \mathrm{S}$ ) were selected according to two complementary criteria, one involving the distance of the float to the isobath $800 \mathrm{~m}$, the other involving the angle between the float trajectory and the isobath $800 \mathrm{~m}$. A first pre-selection was nevertheless done after observing that in the area $5^{\circ} \mathrm{S}-10^{\circ} \mathrm{S}$ where the continental slope is steepest, the offshore boundary of the IWBC is approximately above the $3500 \mathrm{~m}$ isobath (Schott et al., 2002; Schott et al., 2005). We pre-selected those float positions that were inshore of this isobath and, also rejecting a few cases in which the float pressure exceeded $1100 \mathrm{dbar}$ (regarded as the lower limit of the AAIW), were left with an ensemble of 9082 positions that was used to analyze the angle and distances of the float trajectories with the bathymetry.

The angle $(\alpha)$ between the bathymetry and the float trajectory was defined in the range $\left[-180^{\circ}+180^{\circ}\right]$ according to the schematics of Figure $4 \mathrm{a}$. An $\alpha$ value close to zero corresponds to a float moving almost parallel to the reference isobath with the shallow topography on its left, as is the case for the IWBC. Values close to $+180^{\circ}$ or $-180^{\circ}$ correspond to float motions with the shallow topography on the right, as in the Brazil Current or the counter currents offshore of the IWBC. As mentioned above we chose the isobath $800 \mathrm{~m}$ (at its location closest to the float position) as the reference isobath for the computation of $\alpha$. We observed, however, that choosing the isobath underlying the float gave quite similar results. We used the bathymetric data of Smith and Sandwell (1997) gridded with a 2' resolution, that we smoothed using a 2D-Gaussian filter with a $10 \mathrm{~km}$ standard deviation, in order to have the isobath filtered similarly to the float trajectories. This filtered isobath was only used for the computation of $\alpha$, the unfiltered isobath being retained to calculate the float distances to the continental slope.

a) Floats in the IWBC

The angles thus computed at all float positions inshore of the $3500 \mathrm{~m}$ isobath, and north of $27^{\circ} \mathrm{S}$, are shown in Figure $4 \mathrm{~b}$ in relation to the (shortest) float distance to the isobath 
$800 \mathrm{~m}$, and limiting the graph to the range $\left[-90^{\circ}+90^{\circ}\right]$. The cloud of points in this diagram shows a well-defined high-density area at $|\alpha|<30^{\circ}$ and within a few tens of kilometres from the bathymetry. This being the obvious signature of the IWBC, we chose, after some sensitivity tests, to only regard as belonging to the IWBC those positions of the float trajectories for which $|\alpha|<30^{\circ}$.

Figure $4 \mathrm{~b}$ also confirms that the preliminary choice to limit the analysis to the float positions inshore of the isobath $3500 \mathrm{~m}$ should be changed for a more selective criterion. In cases of moderate continental slopes where this isobath is distant from the shelf break (as between the Santos Plateau and the VTR), trajectory segments parallel to the bathymetry are selected in Figure 4b although they are well offshore of the IWBC. Using an isobath-based criterion, the selection of float positions is also distorted by the presence of seamounts. We chose, therefore, to change for a criterion based on the distance of the float to the isobath 800 $\mathrm{m}$. In Figure $4 \mathrm{c}$ is shown the histogram of the float distances to this isobath, for all floats in the angle interval $|\alpha|<30^{\circ}$. As expected, a pronounced peak is observed right against the slope (note the few "negative distances" resulting from uncertainties in the float positioning), seaward of which the curve decreases to $\sim 85 \mathrm{~km}$, and stabilizes to weak values at greater distances. Geostrophic computations using 11 hydrographic sections transverse to the IWBC (not shown) similarly suggested a current width not exceeding $100 \mathrm{~km}$. Stramma et al. (1995), using ADCP measurements, found IWBC widths of $\sim 55 \mathrm{~km}$ at $9^{\circ} \mathrm{S}-10^{\circ} \mathrm{S}$, and $90 \mathrm{~km}$ at $5^{\circ} 30^{\prime} \mathrm{S}$. Schott et al. (1998) observed a width of $\sim 110 \mathrm{~km}$ at $10^{\circ} \mathrm{S}$ and $\sim 60 \mathrm{~km}$ at $5^{\circ} \mathrm{S}$ on averaged hydrographic sections, and Schott et al. (2005) measured $52 \mathrm{~km}(54 \mathrm{~km})$ at $11^{\circ} \mathrm{S}$ $\left(5^{\circ} \mathrm{S}\right)$. Referring to Figure $4 \mathrm{c}$ and to these additional local observations, we retained $85 \mathrm{~km}$ as the distance criterion for the selection of floats in the IWBC.

A total of 4465 SAMBA float positions were found to be distant from the isobath 800 $\mathrm{m}$ by less than $85 \mathrm{~km}$, of which 4106 were located north of the Santos bifurcation. Of these, 2165 that were associated with a trajectory angle (relative to the bathymetry) in the interval [$30^{\circ} ;+30^{\circ}$ ], were regarded as being in the IWBC. Their spatial distribution is shown in Figure 5 (yellow dots), along with the float trajectories during the corresponding 2- or 3-month measurement cycles. The IWBC was well sampled from $27^{\circ} \mathrm{S}$ to the Vitoria-Trindade seamounts at $20^{\circ} 30^{\prime} \mathrm{S}$. A relatively weaker number of positions were selected between this latitude and $15^{\circ} \mathrm{S}$, which might reflect a boundary current not so well defined there. It should also be noted that the complex bathymetric configuration of that area impeded the localization 
of some floats. Farther north, a greater number of selected positions is again found north of $15^{\circ} \mathrm{S}$, and to $\sim 5^{\circ} \mathrm{S}$. The IWBC sampling extends still farther to $\sim 8^{\circ} \mathrm{N}$, yet by a lower number of float positions.

Figure 6 showing the number of selected positions as function of the curvilinear distance to the point located at $27^{\circ} \mathrm{S}$ and $800 \mathrm{~m}$ depth on the continental slope, illustrates the sampling heterogeneity more precisely. The positions selected in the IWBC belong to 45 distinct floats corresponding to the different horizontal lines on the same Figure. On each line are drawn one or several segments representing continuous sections of float trajectories within the IWBC. The continuous trajectory segments are constituted of successive daily positions from a same float that were selected as being in the boundary flow. Continuous trajectory sections only separated by three, or less, non-selected daily positions were, nevertheless, grouped into a single one. Also, when a continuous section of trajectory was interrupted at the end of a measurement cycle (by a 2 or 3-day surfacing of the float), and the beginning of the following cycle was also selected in the IWBC, the two series of positions were united.

\section{b) Floats in the Brazil Current}

Looking for float positions satisfying the IWBC criteria $\left(|\alpha|<30^{\circ}\right.$ and distance to the $800 \mathrm{~m}$ isobath smaller than $85 \mathrm{~km}$ ), only 38 positions (out of 2203) were found south of $27^{\circ} \mathrm{S}$. On examination, these were observed to belong to looping trajectories of two floats entrained in eddies, and in any way did not indicate a northward boundary flow at these latitudes. The weak number of SAMBA floats that sampled the region south of the Santos bifurcation therefore corroborate the result of Boebel et al. (1997), that no direct northward flow of AAIW along the continental slope takes place between the Brazil-Malvinas confluence region near $40^{\circ} \mathrm{S}$ (Gordon, 1989) and the Santos bifurcation.

Looking for the floats that sampled the Brazil Current, we used a similar method as for the IWBC. Based on hydrographic sections transverse to the current at these latitudes (e.g., Zemba, 1991), we chose a rather conservative distance criterion of $450 \mathrm{~km}$ (to the isobath 800 $\mathrm{m})$, the angle criterion now being $\left[\alpha>150^{\circ}\right.$ or $\left.\alpha<-150^{\circ}\right]$. This led to 266 positions south of $28^{\circ} \mathrm{S}$ (green in Figure 5) and belonging to 16 floats (Fig. 6). The Brazil Current at intermediate levels is perturbed by mesoscale features between $28^{\circ} \mathrm{S}$ and $35^{\circ} \mathrm{S}$, where the 800 $\mathrm{m}$ isobath shows some irregularities. As expected, the floats separate from the continental slope near $40^{\circ} \mathrm{S}$, at the Brazil-Malvinas confluence. This sampling of the intermediate Brazil 
Current is too limited to provide reliable results on the transverse flow structure. We simply observe that the few available floats all sampled this current inshore of $150 \mathrm{~km}$. As seen in the following Section, however, they allowed us to extend the description of the meridional structure of the intermediate boundary flows to the domain $28^{\circ} \mathrm{S}-40^{\circ} \mathrm{S}$.

\section{IV - Meridional structure of the intermediate boundary flows}

In Figure 7 are displayed the instantaneous velocity components parallel to the (smoothed) isobath $800 \mathrm{~m}$, as function of the curvilinear abscissa along this isobath. The points in the Figure are associated with all float positions selected as being in the IWBC and the intermediate Brazil Current (south of $28^{\circ} \mathrm{S}$ ). Using the curvilinear abscissa allows one to follow the current in areas where nearly zonal isobaths prevent to use latitude, as in the submarine bight located at $20^{\circ} \mathrm{S}$ west of the VTR (Fig. 1a). Thick lines represent the averaged velocities, computed in alongshore $100 \mathrm{~km}$ intervals.

The floats selected in the Brazil Current exhibit a poleward increase of their mean velocity, from $\sim 0.1 \mathrm{~ms}^{-1}$ at $28^{\circ} \mathrm{S}$ to $\sim 0.25 \mathrm{~ms}^{-1}$ at $36^{\circ} \mathrm{S}$. Farther south, isolated individual velocities reach up to $0.75 \mathrm{~ms}^{-1}$ at $41^{\circ} \mathrm{S}$, the highest velocity recorded during the SAMBA experiment, associated with a float which was leaving the western boundary. Turning to the IWBC, Figure 7 shows relatively stable average velocities of $0.1-0.15 \mathrm{~ms}^{-1}$ south of $24^{\circ} \mathrm{S}$ over the Santos Plateau, increasing equatorward to nearly $0.3 \mathrm{~ms}^{-1}$ before crossing the VTR at $20^{\circ} 30^{\prime} \mathrm{S}$, with some individual velocities exceeding $0.5 \mathrm{~ms}^{-1}$ at this location. Between $20^{\circ} \mathrm{S}$ and $18^{\circ} \mathrm{S}$ a reduced sampling goes along with a slowing down of the current, to less than 0.2 $\mathrm{ms}^{-1}$ at $18^{\circ} \mathrm{S}$. Practically no float positions are selected as being in the IWBC at $18^{\circ} \mathrm{S}-15^{\circ} \mathrm{S}$, in an area where the orientation of the continental slope shows strong variations, at the northeastern corner of the Abrolhos Bank $\left(18^{\circ} \mathrm{S}\right)$, and at the Royal Charlotte Bank $\left(16^{\circ} \mathrm{S}\right)$. The IWBC re-forms at $15^{\circ} \mathrm{S}$, with averaged velocities of $0.08 \mathrm{~ms}^{-1}$ increasing to $\sim 0.20 \mathrm{~ms}^{-1}$ (with individual values up to $0.7 \mathrm{~ms}^{-1}$ ) at $10^{\circ} \mathrm{S}$. North of this latitude, the approach of the equator is characterized by an irregular decrease (to $\sim 0.05 \mathrm{~ms}^{-1}$ at $\sim 3^{\circ} \mathrm{S}$ ) probably associated with connections to the alternate subequatorial flows (Ollitrault et al., 2006). All over the sampled domain, the standard deviation associated with the IWBC velocities is relatively stable below $0.1 \mathrm{~ms}^{-1}$.

The meridional distribution of the IWBC deduced from the subsurface floats generally matches the available Eulerian measurements, also displayed in Figure 7, and the main 
features of the alongshore AAIW transport variations deduced by Wienders et al. (2000). The flow acceleration observed between $28^{\circ} \mathrm{S}$ and $20^{\circ} \mathrm{S}$ is also present, with comparable intensity, in the measurements of Müller et al. (1998) at $28^{\circ} \mathrm{S}, 23^{\circ} \mathrm{S}$ and $20^{\circ} \mathrm{S}$ (marked by circles in Figure 7). At $24^{\circ} \mathrm{S}$, Silveira et al. (2004) report an IWBC maximum velocity of $0.3 \mathrm{~ms}^{-1}$ (plus sign) similar to the highest float velocities at this latitude. At $22^{\circ} 42^{\prime} \mathrm{S}$ (circle), a $0.22 \mathrm{~ms}^{-1} 5$ month mean value in Silveira et al. (2008) is within $0.04 \mathrm{~ms}^{-1}$ of the float average velocity. At $20^{\circ} \mathrm{S}-15^{\circ} \mathrm{S}$, the observed slowing down of the current matches a similar tendency of the AAIW volume transport in the inversion results of Wienders et al. (2000). Farther north, elements of comparison are the $800 \mathrm{~m}$ averaged velocities from $5 \mathrm{ADCP}$ sections at $11^{\circ} \mathrm{S}$ and 9 sections at $5^{\circ} \mathrm{S}$ in Schott et al. (2005) (marked by crosses in the Figure), an 8-month average of current meter measurements at $11^{\circ} \mathrm{S}$ by Schott et al. (2002) (triangles), and unique ADCP sections at $9-10^{\circ} \mathrm{S}$ and $5^{\circ} 30^{\prime} \mathrm{S}$ by Stramma et al. (1995) (squares). Although one of the latter somewhat deviates from the float averaged velocities (yet matches the individual values), the other Eulerian estimates fit in remarkably with the Lagrangian averaged velocities, and also suggest a slowing down of the IWBC between $11^{\circ} \mathrm{S}$ and $5^{\circ} \mathrm{S}$.

The exchange of water between the western boundary layer and the ocean interior is a likely dominant cause of the alongshore strengthening or weakening of the boundary flow. Interpreting Figure 7 in relation to lateral water exchanges, the southward increase of the intermediate Brazil Current to $\sim 36^{\circ} \mathrm{S}$ and the northward increase of the IWBC to $20^{\circ} \mathrm{S}$ indeed match the latitudinal span of the westward return limb of the subtropical gyre at intermediate levels. The exchange patterns are likely more complex north of $20^{\circ} \mathrm{S}$, with a probable transfer of AAIW from the boundary flow to the ocean interior between $20^{\circ} \mathrm{S}$ and $15^{\circ} \mathrm{S}$, reversed exchanges from $15^{\circ} \mathrm{S}$ to $10^{\circ} \mathrm{S}$, and average draining of the IWBC again north of $10^{\circ} \mathrm{S}$.

Analyzing Figure 7 with regard to the continental slope regularity (Fig.1a) and alongslope mesoscale activity (Fig. 3b), the region $20^{\circ} \mathrm{S}-15^{\circ} \mathrm{S}$ where the IWBC decreases sharply is also where the continental slope isobaths are the most irregular, and the mesoscale activity the most intense, an indication that contorted isobaths influence the flow destabilization which, in turn, contributes to the seaward water transfer. In contrast, the domains $24^{\circ} \mathrm{S}-20^{\circ} \mathrm{S}$ and $15^{\circ} \mathrm{S}-10^{\circ} \mathrm{S}$ where the IWBC accelerates are regions of smooth continental slope isobaths and low mesoscale activity.

\section{V - Transverse structure of the IWBC. Counter currents.}


a) Velocity sections across the boundary current

In order to detect possible counter currents, we here extend the distance criterion to $175 \mathrm{~km}$, an a posteriori justified value chosen after some trials. The transverse structures of the boundary flows are shown in Figure 8 in which the points give the values of the velocity components parallel to the $800 \mathrm{~m}$ isobath, and the region has been divided in 3 latitudinal bands $\left(27^{\circ} \mathrm{S}-20^{\circ} \mathrm{S}, 20^{\circ} \mathrm{S}-15^{\circ} \mathrm{S}, 15^{\circ} \mathrm{S}-5^{\circ} \mathrm{S}\right)$ following the results of the preceding Section.

The IWBC stands out in all three regions with a width of $\sim 50 \mathrm{~km}$, defined as the distance from the $800 \mathrm{~m}$ isobath where the averaged velocity vanishes. Note that this distance is smaller than the $85 \mathrm{~km}$ inferred from Figure 4c, because here negative alongshore velocities are selected which, being numerous at the offshore border of the IWBC, cause a sharper seaward decrease of the averaged velocities. The core of the current reaches averaged velocities of $\sim 0.2 \mathrm{~ms}^{-1}$ in the southern and northern regions, as might be expected from Figure 7 , but does not exceed $0.15 \mathrm{~ms}^{-1}$ in the central domain. The current core is narrower $(\sim 25 \mathrm{~km})$ in the southern area than in the two others $(\sim 45 \mathrm{~km})$, an observation which might be related to similar variations of the first internal Rossby radius $\left(\sim 25 \mathrm{~km}\right.$ at $25^{\circ} \mathrm{S}$ and $\sim 45 \mathrm{~km}$ at $10^{\circ} \mathrm{S}$, estimated from nearby hydrographic data). The average cross section of the continental slope bathymetry also displayed in Figure 8, reveals a significantly lower slope in the southern zone (4.4\% if computed between $600 \mathrm{~m}$ and $1000 \mathrm{~m}$ ) than in the two others $(7.3 \%$ in the central zone and $7 \%$ in the northern one). In the three averaged cross sections the highest IWBC velocity is not observed right at the continental slope, but at 10-20 km from it. Schott et al. (2005) also found velocity maxima at distances $\sim 20 \mathrm{~km}$ from the relief in their averaged flow cross sections at $11^{\circ} \mathrm{S}$ and $5^{\circ} \mathrm{S}$. Their results at $11^{\circ} \mathrm{S}$ reveal a width of $55 \mathrm{~km}$ for the IWBC, similar to the current width at $15^{\circ} \mathrm{S}-5^{\circ} \mathrm{S}$ in Figure 8.

Figure 8, finally, reveals the existence of poleward counter currents in the two extreme regions, with maximum averaged velocities of $\sim 0.05 \mathrm{~ms}^{-1}$ in the southern zone and $\sim 0.08 \mathrm{~ms}^{-1}$ in the northern one, and their outer border at about $150 \mathrm{~km}$ from the $800 \mathrm{~m}$ isobath. In contrast, no counter current is detected in the intermediate zone $\left(20^{\circ} \mathrm{S}-15^{\circ} \mathrm{S}\right)$ where, instead, a $\sim 0.05 \mathrm{~ms}^{-1}$ equatorward flow is present at distances between $110 \mathrm{~km}$ and $175 \mathrm{~km}$ from the 800 $\mathrm{m}$ isobath.

b) The counter current at $15^{\circ} \mathrm{S}-5^{\circ} \mathrm{S}$ 
The counter current in the northern domain was previously observed by Stramma et al. (1995), Stramma and Schott (1999), Boebel et al. (1999a), and Schott et al. (2005), yet without determining whether it originates as a recirculation of the IWBC or is fed from the ocean interior, and whether it itself turns shoreward in the IWBC, or seaward. Whereas two float trajectories in Boebel et al. (1999a) illustrate a possible source in the ocean interior, model results in von Shuckmann (2006) tend to favour an origin in the IWBC. The Lagrangian data are used here for more information on these issues. The float positions that sampled the counter current were first selected, using the angle criteria $\alpha>150^{\circ}$ or $\alpha<-150^{\circ}$, and requiring a distance to the $800 \mathrm{~m}$ isobath between $20 \mathrm{~km}$ and $120 \mathrm{~km}$. A total of 405 float positions were found between $5^{\circ} \mathrm{S}$ and $14^{\circ} \mathrm{S}$ (Fig. 9), at an average distance $85 \mathrm{~km}$ from the $800 \mathrm{~m}$ isobath, and associated with an averaged velocity of $\sim 0.1 \mathrm{~ms}^{-1}$. The latitudinal span of the counter current only slightly exceeds the model-inferred range of $6^{\circ} \mathrm{S}-13^{\circ} \mathrm{S}$ given by von Schuckmann (2006), and the averaged velocity compares well with previous Eulerian values.

In Figure 9a,b are displayed the 90-day trajectory portions that precede the float entries in the counter current, distinguishing those that were in the IWBC (a) from those that were in the ocean interior (b). Out of 31 floats that sampled the counter current, 16 came from the boundary current, and 15 from offshore, suggesting a double origin of the counter current, equally shared between the IWBC and the South Equatorial Current. The entries from the IWBC are distributed between $5^{\circ} \mathrm{S}$ and $12^{\circ} \mathrm{S}$, whereas the inflow from offshore appears more concentrated at $8^{\circ} \mathrm{S}-11^{\circ} \mathrm{S}$, yet with two outliers at $\sim 13^{\circ} 30^{\prime} \mathrm{S}$.

The same approach is used to analyze the fate of the counter current (Fig. 9c,d). Out of 30 floats which drifted out of the counter current, only $9(30 \%)$ entered the IWBC, whereas $21(70 \%)$ escaped seaward. Recirculations in the IWBC were observed between $9^{\circ} \mathrm{S}$ and $14^{\circ} \mathrm{S}$, whereas the eastward escapes took place between $6^{\circ} \mathrm{S}$ and $12^{\circ} 30^{\prime} \mathrm{S}$. The dominant seaward escape matches the model outputs of von Schuckmann (2006), which also favoured this exit. The southern termination of the counter current at $12^{\circ} \mathrm{S}-14^{\circ} \mathrm{S}$, and the preferential seaward exit might be related to the presence of the inner core of the large scale tropical gyre south of these latitudes (at $\left.\sim 12^{\circ} \mathrm{S}-20^{\circ} \mathrm{S}\right)$ near the ocean western boundary. This feature, which is marked by a core of colder water in figure $3 \mathrm{a}$, is associated with a cyclonic circulation. From its location it is expected that the counter current abuts on it at $\sim 13^{\circ} \mathrm{S}$, and is subsequently deviated southeastward by the cyclonic flow.

c) The counter current at $27^{\circ} \mathrm{S}-20^{\circ} \mathrm{S}$ 
In red in Figure 10 are represented 560 float positions that were selected as being in the counter current in the region between $26^{\circ} \mathrm{S}$ and $20^{\circ} 45^{\prime} \mathrm{S}$, requiring their distance to the $800 \mathrm{~m}$ isobath to be between $65 \mathrm{~km}$ and $170 \mathrm{~km}$. Their averaged distance was found to be 115 $\mathrm{km}$, and they were associated with velocities averaging to $0.05 \mathrm{~ms}^{-1}$, about half the velocity of the counter current at $14^{\circ} \mathrm{S}-5^{\circ} \mathrm{S}$.

Similar to what was done for the northern domain, the trajectories upstream and downstream of the counter current were plotted (for 150 days, to account for the slower flow in this region), distinguishing those that are inshore of the counter current from those that are offshore. Out of 19 floats drifting in the counter current, 3 came from the IWBC (Fig.10a), and 16 from the ocean interior (Fig.10b). As the 3 floats that came from the boundary flow rapidly rejoined it again, the IWBC only appears as a punctual source for the counter current in that area. The arrival of floats from the ocean interior (Fig.10b) is regularly distributed in latitude between $25^{\circ} 30^{\prime} \mathrm{S}$ and $21^{\circ} 30^{\prime} \mathrm{S}$, with initial nearly zonal trajectories corresponding to the northern limb of the subtropical gyre, turning southwestward when approaching the boundary.

The downstream trajectories (Fig.10c,d) show that, of 18 floats that escaped the counter current, 14 joined in with the IWBC, and 4 escaped seaward. It should be noted that these 4 floats, when tracked downstream of the counter current for more than 150 days, were seen to also eventually enter the IWBC. In all cases, therefore, the southwestward counter current in this region appears as a link between the return westward flow of the subtropical gyre and the IWBC, a configuration already represented in the flow schematics of Boebel et al. (1999b). The entry in the IWBC always takes place south of $23^{\circ} \mathrm{S}$.

\section{VI - The Santos bifurcation and the region $20^{\circ} \mathrm{S}-15^{\circ} \mathrm{S}$}

a) The Santos bifurcation

Two bunches of floats launched during the SAMBA experiment at $22^{\circ} 30^{\prime} \mathrm{S}, 33^{\circ} \mathrm{W}$ and $26^{\circ} 30^{\prime} \mathrm{S}, 36^{\circ} \mathrm{W}$ (Fig.11) provide data that complement the original description of the Santos bifurcation by Boebel et al. (1997) and Boebel et al. (1999a). A first suggestion drawn from Figure 11a, is that the bifurcation does not occur right at the continental slope, but farther offshore. This is apparent in the trajectories of the floats that were launched at $26^{\circ} 30^{\prime} \mathrm{S}$, which sampled both the southbound and northbound branches of the flow. While some of them no sooner reached $40^{\circ} \mathrm{W}$ than they turned southwestward along the southern side of the Plateau 
and rejoined the Brazil Current at $28^{\circ} \mathrm{S}$, others proceeded westward along the northern flank of the Plateau, and were entrained in the IWBC at $27^{\circ} \mathrm{S}$. From Figure 11 the bifurcation, that is, the location where the westward flow diverge to feed the two opposite boundary currents, occurs near $26^{\circ} 30^{\prime} \mathrm{S}-41^{\circ} \mathrm{W}$, at the northeastern corner of the Santos Plateau. Southwest of this location, no float drifted between $27^{\circ} \mathrm{S}$ and $28^{\circ} \mathrm{S}$ in the submarine bight south of the Plateau, which looks like a "forbidden" area for the floats. The Brazil Current at intermediate levels itself originates at $28^{\circ} \mathrm{S}$, and the IWBC at $27^{\circ} \mathrm{S}$, southwest of the Plateau. While the floats arriving from the east seem constrained to skirt the bathymetry, others arriving from the north manage to flow over it. They do it, however, in a perturbed way, being entrained in anticyclonic eddies when arriving over the Plateau. This change of dynamical regime over the Santos Plateau, relative to its surroundings, is reflected in Figure $3 \mathrm{~b}$ by a localized EKE maximum.

Figure $11 \mathrm{~b}$ showing the SAMBA float velocities averaged in $1^{\circ} \mathrm{x} 1^{\circ}$ boxes exhibits the major flow characteristics just discussed from the trajectories. The mean averaged velocities east of $39^{\circ} \mathrm{W}$ and between $30^{\circ} \mathrm{S}$ and $21^{\circ} \mathrm{S}$ is $0.023 \mathrm{~ms}^{-1}$, slightly below the $0.03 \mathrm{~ms}^{-1}$ value measured by Boebel et al. (1999a) at $30^{\circ} \mathrm{S}$. Along the continental slope, the two boundary flows rapidly accelerate away from their formation locations, reaching mean velocities above $0.15 \mathrm{~ms}^{-1}$ at $30^{\circ} \mathrm{S}$ for the intermediate Brazil Current, and at $26^{\circ} \mathrm{S}$ for the IWBC. The flow variability, characterised by the principal variances (not shown), confirms the stability of the westward flow approaching the slope on either side of the Plateau and, in contrast, the high variability over the topography. Eulerian 700-day averaged velocities from a current meter array deployed during WOCE (Müller et al., 1998; Hogg et al., 1999), fit in quite well with the Lagrangian velocities (Fig.11b). The most inshore instrument, located at $27^{\circ} 54^{\prime} \mathrm{S}$ $46^{\circ} 42^{\prime} \mathrm{W}$ near the southern border of the region not visited by the floats, shows, as expected, no significant averaged alongshore component.

The float averaged velocities shown in Figure $11 \mathrm{~b}$ were used in different manners to estimate the AAIW volume transport associated with the westward limb of the subtropical gyre. First referencing the geostrophic velocities of the WOCE/A17 hydrographic section (CTD station positions given by "+" signs in Figure 11b) to these velocities north of $30^{\circ} \mathrm{S}$ and, following Wienders et al. (2000), to the upper boundary of the North Atlantic Deep Water (isopycnal $\sigma_{2}=36.83 \mathrm{~kg} \mathrm{~m}^{-3}$ ) south of this latitude, the westward return current of the subtropical gyre was found to extend from $33^{\circ} 30^{\prime} \mathrm{S}$ to $20^{\circ} 30^{\prime} \mathrm{S}$, and to transport $10.6 \mathrm{~Sv}$ of 
AAIW westward. This value, obtained by assuming a $~ 430 \mathrm{~m}$ thickness of the AAIW layer (between isopycnals $\sigma_{0}=27.0 \mathrm{~kg} \mathrm{~m}^{-3}$ and $\sigma_{1}=31.0 \mathrm{~kg} \mathrm{~m}^{-3}$ ), is lower than the $23^{\circ} \mathrm{S}-33^{\circ} \mathrm{S}$ estimate of $15 \mathrm{~Sv}$ by Boebel et al. (1997), who used a different (less numerous) set of floats, and a thickness of $500 \mathrm{~m}$ for the water mass. Limiting the computation to the domain north of $30^{\circ} \mathrm{S}$ where SAMBA floats were available, the volume transport reduces to $8.1 \mathrm{~Sv}$, comparable to the value $7.9 \mathrm{~Sv}$ obtained by using all mean float velocities from the domain [20 $30^{\circ} \mathrm{S}-30^{\circ} \mathrm{S}, 26^{\circ} \mathrm{W}-39^{\circ} \mathrm{W}$ ] (shown as a rectangle in Figure $11 \mathrm{~b}$ ). In order to determine how this westward AAIW transport splits up between the northbound and southbound boundary flows, similar geostrophic computations were carried out using the hydrographic WOCE/A19 section perpendicular to the boundary at $19^{\circ} \mathrm{S}$ (referencing the geostrophic currents to the float velocities), and a "Marathon" section across the Brazil current at $31^{\circ} \mathrm{S}$ (Zemba, 1991; assuming zero alongshore velocity at the base of the North Atlantic Deep Water). The computation gave $3.4 \mathrm{~Sv}$ for the IWBC at $19^{\circ} \mathrm{S}$, and $5.4 \mathrm{~Sv}$ for the AAIW in the Brazil Current at $31^{\circ} \mathrm{S}$, two values which sum up to $8.8 \mathrm{~Sv}$, close to the above $30^{\circ} \mathrm{S}-20^{\circ} 30^{\prime} \mathrm{S}$ transport estimate. Relating the $3.4 \mathrm{~Sv}$ transport of the IWBC at $19^{\circ} \mathrm{S}$ to the total $10.6 \mathrm{~Sv}$ of the return limb of the subtropical gyre, these estimates suggest that one third of the latter turns northward, while two third of it recirculates southward in the subtropical western boundary current. This ratio is somewhat higher than the one-to-four ratio proposed by Schmid et al. (2000), which, however, applied to a higher incoming flow of $19 \mathrm{~Sv}$.

b) Flow of AAIW near the western boundary at $20^{\circ} \mathrm{S}-15^{\circ} \mathrm{S}$

The analyses of the meridional and transverse structures of the IWBC in Sections 4 and 5 both suggest a change of flow regime at latitudes $20^{\circ} \mathrm{S}-15^{\circ} \mathrm{S}$, where the current is weaker (Fig.7, 8) and associated with a higher mesoscale activity (Fig.3b). In this Section we try to determine to which extent these perturbations, likely caused by a contorted continental slope geometry, affect the continuity of the boundary flow and its exchanges with the ocean interior.

\section{Continuity of the IWBC across the $20^{\circ} \mathrm{S}-15^{\circ} \mathrm{S}$ domain}

Out of 16 floats that sampled the IWBC between $27^{\circ} \mathrm{S}$ and the VTR, 8 further sampled the boundary flow north of $15^{\circ} \mathrm{S}$. The fact that half of the floats sampled the boundary flow south of $20^{\circ} \mathrm{S}$ and north of $15^{\circ} \mathrm{S}$, however, does not imply that there exists a continuous alongshore branch of the flow. Figure 12, which displays the trajectories of the 24 floats that 
drifted through the region between VTR and $18^{\circ} \mathrm{S}$, and west of $36^{\circ} \mathrm{W}$, shows that the floats originating in the IWBC south of $20^{\circ} \mathrm{S}$ left the boundary for some time between $20^{\circ} \mathrm{S}$ and $15^{\circ} \mathrm{S}$, being entrained offshore by the intense mesoscale variability of the region.

Despite these disruptions of the IWBC, however, about half of the particles flowing in the boundary current south of the VTR rejoin the boundary north of $15^{\circ} \mathrm{S}$ after a detour in the ocean interior. The latitudes where the floats are re-entrained into the IWBC are naturally influenced by their positions of launching, so that no totally objective statistical result on these entry locations can be inferred. In Figure 13, however, the latitudes $15^{\circ} \mathrm{S}-13^{\circ} \mathrm{S}$ stand out as a preferential location of entrainment in the IWBC. Out of 12 floats that rejoined the boundary current north of $18^{\circ} \mathrm{S}, 11$ did it in this short latitudinal interval. This location therefore appears as the place where the IWBC re-forms, either fed from the ocean interior (including the energetic domain at $20^{\circ} \mathrm{S}-15^{\circ} \mathrm{S}$ ), or from the $5^{\circ} \mathrm{S}-14^{\circ} \mathrm{S}$ counter current.

\section{AAIW northward crossing of the Vitoria Trindade Ridge}

At $20^{\circ} \mathrm{S}$, the IWBC flows cyclonically along a wide southward-oriented submarine bight, that terminates at $38^{\circ} 12^{\prime} \mathrm{W}$ at the westernmost passage across the VTR (Fig.12). Müller et al. (1998) measured AAIW equatorward mean speeds of $0.21 \mathrm{~ms}^{-1}$ in this $950 \mathrm{~m}$ deep passage, yet suggested that a part of the northward transport of the water mass takes place farther east in the other passages across the ridge. Of the 11 floats that drifted in the IWBC upstream of the westernmost passage, 9 turned into it, and 2 proceeded farther along the southern flank of the ridge. An attempt to relate various float parameters to these different behaviours was fruitless. No relation to the velocity was found. The distance of the floats to the $800 \mathrm{~m}$ isobath might also have had an effect (Leaman and Vertes, 1996), depending on whether the instrument was inshore of the current core, in the anticyclonic relative vorticity domain of the boundary flow, or farther offshore in the cyclonic domain. This was not the case, however, as the two floats that drifted past the passage were at similar distances from the $800 \mathrm{~m}$ isobath as the others, and were themselves separated by $12 \mathrm{~km}$. It so happened that the two instruments drifted past the passage the same day, so that the ambient flow, notably the nearby presence of the so-called Vitoria eddy (Schmid et al., 1995), might be what caused the behaviour. This feature is a cyclonic eddy developing in the afore-mentioned submarine bight as the consequence of coastal upwelling events between $22^{\circ} \mathrm{S}$ and $20^{\circ} \mathrm{S}$.

\section{The energetic domain north of the Vitoria Trindade Ridge}


Figure 12 illustrates also the sharp contrast between the IWBC-dominated flow regime south of the ridge, and a very irregular flow north of it. The swirling trajectories in the latter domain corroborate previous inferences drawn by Weatherly et al. (2000) from Eulerian measurements at $900 \mathrm{~m}$ depth and $18^{\circ} \mathrm{S}$, that the intermediate flow is highly turbulent in this region. There exists, however, an extension of the IWBC north of the VTR, particularly between $20^{\circ} \mathrm{S}$ and the northeastern corner of the Abrolhos Bank at $18^{\circ} \mathrm{S}$. Some floats, (yellow trajectories in Figure 12) drifted alongside the continental slope over the totality of this latitude interval, while others (red) only rejoined the boundary flow at $19^{\circ} \mathrm{S}$. The former almost exclusively originate in the IWBC south of $20^{\circ} \mathrm{S}$, and the latter equitably originate in the boundary flow and the ocean interior. All of them but one leave the boundary at $18^{\circ} \mathrm{S}$, the domain $18^{\circ} \mathrm{S}-15^{\circ} \mathrm{S}$ being apparently devoid of a boundary flow.

While many floats left the boundary current on crossing the VTR at $20^{\circ} 30^{\prime} \mathrm{S}$, the net zonal exchanges farther offshore across $36^{\circ} \mathrm{W}$ and between $20^{\circ} \mathrm{S}$ and $18^{\circ} \mathrm{S}$ (Fig.12) seem to be shoreward, as this was the direction of 8 floats out of 11 that crossed this meridional segment. On the other hand, all 17 floats that intersected $18^{\circ} \mathrm{S}$ between the continental slope and the Hotspur seamount at $36^{\circ} \mathrm{W}$ did it equatorward, an indication that, despite its pronounced offshore mesoscale activity, this area remains one of northward AAIW transfer.

The transition from the domain $18^{\circ} \mathrm{S}-15^{\circ} \mathrm{S}$ with possibly no boundary current, to the region north of $15^{\circ} \mathrm{S}$, where the IWBC exists again, occurs as depicted in Figure 13, through an anticyclonic circulation centred at $\sim 15^{\circ} 30^{\prime} \mathrm{S} / 37^{\circ} \mathrm{W}$. This feature was sampled by 10 sections of trajectories from different periods, an indication that it is stationary. It has a rotation period of $\sim 45$ days, average radius of $90 \mathrm{~km}$, and average swirl velocity of $0.14 \mathrm{~m} \mathrm{~s}$ 1. It is (at least partly) fed from the northward flow at $18^{\circ} \mathrm{S}$, and in turn partly feeds the IWBC at $15^{\circ} \mathrm{S}$.

\section{VII - Locations of IWBC inputs and outputs. Transit times.}

\section{a) IWBC inputs and outputs}

The meridional structure of the IWBC is reflected in the meridional distributions of the current inputs and outputs shown in Figure 14. Here the locations where the floats entered or exited the IWBC are defined as the first and last positions of the IWBC trajectory segments, only requiring these segments to last more than 10 days. These occurrences were counted in each $1^{\circ}$ latitudinal interval, and their ratio to the total number of float positions in 
that interval computed. Figure 14 shows these ratios (green for inputs and red for outputs), along with the ratio corresponding to floats that just passed the latitude range in the IWBC (without entering of leaving it).

In keeping with the above descriptions, two regions stand out as being important locations of entry in the IWBC. The first one, from $27^{\circ} \mathrm{S}$ to $\sim 22^{\circ} 30^{\prime} \mathrm{S}$, is where the IWBC originates and is first fed from the return limb of the subtropical gyre. We observe that, while this interior flow extends northward to $\sim 20^{\circ} \mathrm{S}$, the entry into the boundary current only extends to $22^{\circ} 30^{\prime} \mathrm{S}$, a consequence of the southwestward orientation of the intervening counter current. The other dominant entry location is at $15^{\circ} \mathrm{S}-12^{\circ} \mathrm{S}$, where the IWBC reforms. The peak at $15^{\circ} \mathrm{S}-14^{\circ} \mathrm{S}$ in the entry curve (all recorded float positions are entry points at these latitudes) shows the sharp transition between the area with no IWBC at $18^{\circ} \mathrm{S}-15^{\circ} \mathrm{S}$, and the region north of $14^{\circ} \mathrm{S}$ where the boundary flow is well-defined again. Unlike the southern entry region, the area $15^{\circ} \mathrm{S}-12^{\circ} \mathrm{S}$ where the IWBC re-forms is not associated with any large scale westward flow from the ocean interior. As pointed out above, a major source of this northern section of the IWBC is the energetic offshore area at $20^{\circ} \mathrm{S}-18^{\circ} \mathrm{S}$, another one being the counter current at $14^{\circ} \mathrm{S}-5^{\circ} \mathrm{S}$.

Four regions show a majority of seaward escape float locations in Figure 14: At $20^{\circ} \mathrm{S}$, where a part of the floats that crossed the westernmost passage of VTR are entrained seaward by the local intense mesoscale activity; at $18^{\circ} \mathrm{S}-17^{\circ} \mathrm{S}$, downstream of the $18^{\circ} \mathrm{S}$ abrupt change of orientation of the continental slope; at $8^{\circ} \mathrm{S}$ north of the Recife Plateau, and at $5^{\circ} 30^{\prime} \mathrm{S}$ near the Cape Sao Roque. It is noticeable that these regions of dominant seaward escape of the floats all correspond to the presence of capes in the continental slope geometry. Figure 14 showing the curvature of the smoothed $800 \mathrm{~m}$ isobath from $27^{\circ} \mathrm{S}$ to $6^{\circ} \mathrm{S}$, reveals three outstanding capes at $20^{\circ} \mathrm{S}, 18^{\circ} \mathrm{S}$, and $16^{\circ} \mathrm{S}$, two of which are locations of escape from the IWBC, the third one (the Royal Charlotte Bank at $16^{\circ} \mathrm{S}$ ) being in the latitude range $18^{\circ} \mathrm{S}-15^{\circ} \mathrm{S}$ where the boundary flow probably does not exist. The Cape São Roque at $\sim 5^{\circ} S$ is another location of pronounced isobath curvature. The Recife Plateau at $\sim 8^{\circ} \mathrm{S}$ is only associated with a moderate curvature peak, yet significantly higher curvatures of the deeper isobaths (e.g., $1500 \mathrm{~m}$, not shown) at this location likely influence the flow at $800 \mathrm{~m}$. Figure 15 illustrates the numerous exits from the boundary current, that take place in the vicinity of the Recife Plateau. In Figure 14, two less pronounced curvature peaks at $23^{\circ} 30^{\prime} \mathrm{S}$ (Cape Frio) and $22^{\circ} \mathrm{S}$ (Cape São Tomé) only correspond, from the float trajectories, to occasional instabilities of the 
flow at $800 \mathrm{~m}$, although instabilities were observed there at shallower levels (Silveira et al., 2008; see the discussion in Section VIII).

\section{b) Float residence times in the IWBC. Transit times.}

The SAMBA data are particularly suitable for an analysis of the transit time of water in the IWBC, an important issue given the role of this current in transporting water and associated property anomalies meridionally. First referring back to the continuous trajectory sections shown in Figure 6, the averaged duration of these sections (or float residence time in the boundary flow) was estimated to 12 days, with a maximum of 73 days (the latter taking place between latitudes $15^{\circ} \mathrm{S}$ and $\left.2^{\circ} \mathrm{S}\right)$. Only retaining the distance criterion $(<85 \mathrm{~km})$ to define the IWBC, the average residence time increased to 22 days, and its maximum value to 175 days. The averaged continuous curvilinear distance in the boundary current was found to be $167 \mathrm{~km}$, and the largest one, of $\sim 1200 \mathrm{~km}$, corresponds to the portion of yellow trajectory between $13^{\circ} \mathrm{S}$ and $4^{\circ} \mathrm{S}$ in Figure 2.

In order to discuss the time taken by the floats to progress equatorward near the South Atlantic western boundary, we divided the total latitudinal span of the IWBC in four domains according to the above description of the current, and only retained those floats that were in the boundary current at the entry and exit of each domain (first four lines in Table 1), whatever their intervening routes (in the boundary flow or not). The transit times reported in Table 1 illustrate the different flow regimes prevailing near the western boundary in the four areas. In the two regions $24^{\circ} \mathrm{S}-20^{\circ} 30^{\prime} \mathrm{S}$ and $14^{\circ} \mathrm{S}-5^{\circ} \mathrm{S}$ where the continental slope is regular and the IWBC well-defined, the relatively short transit times (42 days and 72 days) associated with low standard deviations are indicative of direct transits. Given the alongshore distances along these paths, the float velocities averaged over these distances are $0.15 \mathrm{~ms}^{-1}$ and $0.18 \mathrm{~ms}^{-}$ ${ }^{1}$ along the southern and northern sections, respectively. These values compare well with averaged Eulerian velocities of the IWBC in the same areas, namely, $0.122 \mathrm{~ms}^{-1}$ at $23^{\circ} \mathrm{S}$ by Müller et al. (1998), and $0.187 \mathrm{~ms}^{-1}$ at $11^{\circ} \mathrm{S}$ by Schott et al. (2002). The longer transit time (201 days) and higher associated standard deviation at $20^{\circ} \mathrm{S}-16^{\circ} \mathrm{S}$, on the other hand, reflect the circuitous float trajectories in this turbulent region. The averaged net alongslope velocity there is only $0.03 \mathrm{~ms}^{-1}$. The only float that flowed throughout the interval $5^{\circ} \mathrm{S}-0^{\circ} \mathrm{S}$ did it an averaged velocity of $0.11 \mathrm{~ms}^{-1}$, also indicative of a relatively well-defined IWBC. Finally, three floats that entered the IWBC at $23^{\circ} 30^{\prime} \mathrm{S}$ and were also observed in the current at $5^{\circ} \mathrm{S}$, 
suggest that about one year is needed to cover the distance from the IWBC formation area to the location where it branches into the zonal equatorial jets (Table 1).

\section{VIII - Summary and discussion}

Owing to more than 2000 velocity estimates distributed over the whole extent of the IWBC, the SAMBA float data have revealed a latitudinal structure of this current in three main regimes, influenced by the ocean interior circulation, and by the continental slope configuration. The current originates at $27^{\circ} \mathrm{S}$ along the continental slope from a bifurcation of the return westward limb of the subtropical gyre, which itself seems to take place slightly upstream at the northeast corner of the Santos Plateau. The boundary current is well defined along relatively smooth isobaths from $27^{\circ} \mathrm{S}$ to the Vitoria-Trindade Ridge (VTR) at $20^{\circ} 30^{\prime} \mathrm{S}$. Sharp variations of the continental slope orientation cause a partial water escape from the boundary at $20^{\circ} \mathrm{S}$, and a nearly total separation at $18^{\circ} \mathrm{S}$, resulting in a weaker IWBC on average, and strong offshore mesoscale activity between $20^{\circ} \mathrm{S}$ and $15^{\circ} \mathrm{S}$. The boundary flow re-forms spectacularly at the latter latitude, from a recirculating southward counter current, from offshore water, and also from water that already flowed along the boundary south of $20^{\circ} \mathrm{S}$, and was entrained in the offshore turbulent regime at $20^{\circ} \mathrm{S}-15^{\circ} \mathrm{S}$. The IWBC is welldefined again from $15^{\circ} \mathrm{S}$ to $5^{\circ} \mathrm{S}$, reaching maximum velocities at $12^{\circ} \mathrm{S}-10^{\circ} \mathrm{S}$, then decreasing when drained by the counter current and by the equatorial zonal jets north of $\sim 5^{\circ} \mathrm{S}$.

Transversally, the current width is everywhere less than $100 \mathrm{~km}$, with a maximum velocity at $\sim 20 \mathrm{~km}$ from the $800 \mathrm{~m}$ isobath. Counter currents of $0.05 \mathrm{~ms}^{-1}-0.1 \mathrm{~ms}^{-1}$ average magnitude exist offshore of the IWBC in the two regions of smooth lateral bathymetry $\left(27^{\circ} \mathrm{S}\right.$ $\left.20^{\circ} 30^{\prime} \mathrm{S}, 14^{\circ} \mathrm{S}-5^{\circ} \mathrm{S}\right)$. In the intervening domain of rougher topography the counter current is replaced by an intense mesoscale variability with net equatorward transport. The float data suggest different relations of the two counter currents with the boundary flow: While the southern one feeds the IWBC with water collected from the return limb of the subtropical gyre, the northern one, being partly fed from inshore and terminating mostly seaward, should have a net draining effect on the boundary flow. The different flow regimes in the three subregions of the IWBC influence the float transit times. While on average the floats take 40 and 70 days to cross the southern and northern domains, respectively, they take 200 days to 
traverse the central region, a time that may vary between 30 and 1000 days, depending on whether they partly follow the boundary or get totally entangled in the offshore-prevailing mesoscale activity. Based on 3 trajectories, the overall transit time at intermediate levels from the IWBC formation location at $27^{\circ} \mathrm{S}$ to the equatorial region is one year on average.

It must be borne in mind, that the SAMBA floats provide only 90-day continuous deep trajectories (at most), and that surfacings cause the floats to depart from the particles tagged at depth. We do not think however this has corrupted the results obtained, significantly.

Our limiting the above characterization of the IWBC to the along-slope and transverse dimensions naturally only comes of the one-level float data providing no information on the vertical dimension. There is no doubt, however, that attempts to understand the dynamics of most of the above-described features of the IWBC would require examining the whole water column. Considering the intense mesoscale activity revealed by the subsurface floats at latitudes $20^{\circ} \mathrm{S}-15^{\circ} \mathrm{S}$, reference must be made to a recent study by Soutelino et al. (2011), who suggest, on the basis of synoptic hydrographic/ADCP surveys and model outputs, that the near-surface Brazil Current is eddy-dominated north of $20^{\circ} \mathrm{S}$. The authors observed a majority of anticyclones in this region, a result corroborated by the subsurface floats. In the same region, the Eulerian measurements of Weatherly et al. (2000) showed that the mesoscale activity is also present at the deep levels $(1000 \mathrm{~m}-3000 \mathrm{~m})$, superimposed on a southeastward mean flow of North Atlantic Deep Water. Soutelino et al. (2011) mention topographical constraints (by the Abrolhos Bank, VTR and the Royal Charlotte Bank) or geophysical instabilities of the Brazil Current - IWBC opposing flows as potential causes of this intense mesoscale activity. Observing the full-depth character of the flow perturbations, one should probably add the flow reversal at the boundary between intermediate and deep waters in the list of possible factors of instabilities.

Farther south, the Brazil Current was intensively studied in the region of Cape Frio $\left(23^{\circ} \mathrm{S}\right)$ and Cape São Tomé $\left(22^{\circ} \mathrm{S}\right)$ (Silveira et al., 2004, 2008; Fernandes et al., 2009). Although the subsurface floats give the image of a well-defined IWBC there (with a few exit occurrences, though), the above-quoted studies underline near-surface Brazil Current instabilities and developing meandering patterns. Numerical experiments get the authors to the conclusion that these features result from first baroclinic mode instabilities of the Brazil Current - IWBC system. Silveira et al. (2008) observe that, while these instabilities are significant at upper levels, they show a sharp decay with depth, not causing any flow reversal 
in the authors' 900 m near-slope Eulerian measurements. This is corroborated by the image of a relatively stable IWBC given by the SAMBA floats at these latitudes. The surface intensification of the boundary flow instabilities in that region strongly contrasts with the deep-reaching eddy activity at $20^{\circ} \mathrm{S}-15^{\circ} \mathrm{S}$.

In the domain $15^{\circ} \mathrm{S}-5^{\circ} \mathrm{S}$, Dengler et al. (2004) observed, from direct current measurements at $11^{\circ} \mathrm{S}$ and model simulations, that the Deep Western Boundary Current, which flow underneath the IWBC and transports North Atlantic Deep Water southward, breaks up at $\sim 8^{\circ} \mathrm{S}$, under the likely effect of the Recife Plateau. Southward transport of deep water proceeds beyond this latitude, yet is accomplished by migrating eddies, rather than by a continuous flow. Confronting this with the subsurface float observations, we note that the latitudes around $8^{\circ} \mathrm{S}$ were found to be a privileged location of exit from the IWBC (Fig.15). Out of 17 float seaward escapes from the IWBC that took place between $10^{\circ} \mathrm{S}$ and $7^{\circ} 50^{\prime} \mathrm{S}, 7$ occurred in front of the Plateau $\left(\sim 8^{\circ} 15^{\prime} S\right)$, and 10 south (and upstream) of it. The latter suggest a possible influence of the newly-formed deep water eddies, although the floats were generally entrained in the counter current, rather than in eddy-like features. Farther south, there is no particular indication from the floats that the southward propagating eddies might have an effect on the IWBC. From Dengler et al. (2004), the deep vortices show maximum velocities at $\sim 2000 \mathrm{~m}$ and are strongly attenuated at $800 \mathrm{~m}$. Due to the tilt of the continental slope, they are also located offshore of the IWBC rather than below it, another factor that should limit their influence. Some floats did leave the IWBC between $14^{\circ} \mathrm{S}$ and $10^{\circ} \mathrm{S}$ (Fig.15), but they may well have been detrained by the adjacent counter current, rather than by the deep eddies. 


\section{Acknowledgements:}

Support to the WOCE/SAMBA project has been provided by the IFREMER program "Circulation Océanique". J.F. Legeais' contribution to this work was done while a $\mathrm{PhD}$ student at the Laboratoire de Physique des Océans, supported by a grant from the Délégation Générale de l'Armement. M. Ollitrault and M. Arhan were supported by IFREMER.

We are much grateful to Tom Rossby for sharing his knowledge of the RAFOS technology prior to WOCE, which enabled the development of the MARVOR float. 


\section{References:}

Boebel O., Schmid C., Zenk W., 1997. Flow and recirculation of Antarctic Intermediate Water across the Rio Grande Rise. Journal of Geophysical research, 102, 2096720986.

Boebel O., Schmid C., Zenk W., 1999a. Kinematic elements of Antarctic Intermediate Water in the western South Atlantic. Deep-Sea Research II, 46, 355-392.

Boebel O., Davis R.E., Ollitrault M., Peterson R.G., Richardson P.L., Schmid C., Zenk W., 1999b. The intermediate depth circulation of the western South Atlantic. Geophysical Research Letters, 26, 3329-3332.

Boebel O., Lutjeharms J., Schmid C., Zenk W., Rossby T., Barron C., 2003. The Cape Cauldron: a regime of turbulent inter-ocean exchange. Deep-Sea Research II, 50, 5786.

Dengler M., Schott F.A., Eden C., Brandt P., Fisher J., Zantopp R.J., 2004. Break-up of the Atlantic deep western boundary current into eddies at $8^{\circ} \mathrm{S}$. Nature, 432, 1018-1020.

Evans D.L., Signorini S.S., 1985. Vertical structure of the Brazil Current. Nature, 315, 48-50.

Fernandes A.M., Silveira I.C.A., Calado L., Campos E.J.D., Paiva A.M., 2009. A two-layer approximation to the Brazil Current - Intermediate Western Boundary Current system between $20^{\circ} \mathrm{S}$ and $28^{\circ} \mathrm{S}$. Ocean Modelling, 29, 154-158.

Gordon A.L., 1989. Brazil-Malvinas confluence - 1984. Deep-Sea Research, 36, 359-384.

Hogg N.G., Siedler G., Zenk W., 1999. Circulation and variability at the southern boundary of the Brazil Basin. Journal of Physical Oceanography, 29, 145-157.

Leaman K.D., Vertes P.S., 1996. Topographic influences on recirculation in the Deep Western Boundary Current: Results from RAFOS float trajectories between the BlakeBahama Outer Ridge and the San Salvador "Gate". Journal of Physical Oceanography, 26, 941-961. 
Müller T.J., Ikeda Y., Zangenberg N., Nonato L.V., 1998. Direct measurements of western boundary currents off Brazil between $20^{\circ} \mathrm{S}$ and $28^{\circ} \mathrm{S}$. Journal of Geophysical Research, 103, 5429-5437.

Nuñez-Riboni I., Boebel O., Ollitrault M., You Y., Richardson P.L., Davis R., 2005. Lagrangian circulation of Antarctic Intermediate Water in the subtropical South Atlantic. Deep-Sea Research II, 52, 545-564.

Ollitrault M., Auffret Y., Cortes N., Hémon C., Jégou P., Le Reste S., Loaec G., Rannou J., 1995. The SAMBA experiment, vol. 1, SAMBA1 Lagrangian and CTD data. Repères Océan, 12, 488 pp., Ifremer, Brest, France.

Ollitrault M., 1999. MARVOR floats reveal intermediate circulation in the western equatorial and tropical South Atlantic (30S to 5N). International WOCE Newsletter, 34, 7-10.

Ollitrault M., Lankhorst M., Fratantoni D., Richardson P., Zenk W., 2006. Zonal intermediate currents in the equatorial Atlantic Ocean. Geophysical research Letters, 33, L05605, doi:10.1029/2005GL025368.

Reid J.L., 1989. On the total geostrophic circulation of the South Atlantic Ocean: Flow patterns, tracers, and transports. Progress in Oceanography, 23, 149-244.

Richardson P.L., Lutjeharms J.R.E., Boebel O., 2003. Introduction to the "Inter-ocean exchange around southern Africa”. Deep-Sea Research II, 50, 1-12.

Rossby T., Dorson D., Fontaine J., 1986. The RAFOS system. Journal of Atmosphere and Ocean Technology, 3, 672-679.

Schmid C., Schäfer H., Podesta G., Zenk W., 1995. The Vitoria eddy and its relation to the Brazil Current. Journal of Physical Oceanography, 25, 2532-2546.

Schmid C., Siedler G., Zenk W., 2000. Dynamics of Intermediate Water in the subtropical South Atlantic. Journal of Physical Oceanography, 30, 3191-3211.

Schott F.A., Stramma L., Fisher J., 1995. The warm water inflow into the western tropical Atlantic boundary regime, spring 1994. Journal of Geophysical Research, 100, 2574524760. 
Schott F.A., Fischer J., Stramma L., 1998. Transports and pathways of the upper-layer circulation in the western tropical Atlantic. Journal of Physical Oceanography, 28, 1904-1928.

Schott F.A., Brandt P., Hamann M., Fischer J., Stramma L., 2002. On the boundary flow off Brazil at $5-10^{\circ} \mathrm{S}$ and its connection to the interior tropical Atlantic. Geophysical Research Letters, 29(17), 1840.

Schott F.A., Dengler M., Zantopp R., Stramma L., Fischer J., Brandt P., 2005. The shallow and deep western boundary circulation of the South Atlantic at $5^{\circ}-11^{\circ} \mathrm{S}$. Journal of Physical Oceanography, 35, 2031-2053.

Silveira I.C.A., de Miranda L.B., Brown W.S., 1994. On the origins of the North Brazil Current. Journal of Geophysical Research, 99, 22501-22512.

Silveira I.C.A., Calado L., Castro B.M., Cirano M., Lima J.A.M., Mascarenhas A.D.S., 2004. On the baroclinic structure of the Brazil Current - Intermediate Western Boundary Current system at $22^{\circ}-23^{\circ} \mathrm{S}$. Geophysical Research Letters, 31, L14308, doi:10.1029/2004GL020036.

Silveira I.C.A., Lima J.A.M., Schmidt A.C.K., Ceccopieri W., Sartori A., Francisco C.P.F., Fontes R.F.C., 2008. Is the meander growth in the Brazil Current system off southeast Brazil due to baroclinic instability? Dynamics of Atmospheres and Oceans, 45, 187207.

Smith W.H.F., Sandwell D.T., 1997. Global seafloor topography from satellite altimetry and ship depths soundings. Science, 277 (5334), 1956-1962.

Soutelino R.G., Silveira I.C.A., Gangopadhyay A., Miranda J.A., 2011. Is the Brazil Current eddy-dominated north of $20^{\circ} \mathrm{S}$ ? Geophysical research letters, 38, L03607, doi:10.1029/2010GL046276.

Stramma L., Fisher J., Reppin J., 1995. The North Brazil Undercurrent. Deep-Sea Research I, 42, 773-795.

Stramma L., Schott F.A., 1999. The mean flow field of the tropical Atlantic Ocean. Deep-Sea Research II, 46, 279-303. 
Suga T., Talley L.D., 1995. Antarctic Intermediate Water circulation in the tropical and subtropical South Atlantic. Journal of Geophysical Research, 100, 13441-13453.

Von Schuckmann K., 2006. Intraseasonal variability in the southwestern and central tropical Atlantic Ocean. Ph. D. thesis, IFM-GEOMAR an der Universität Kiel, Germany.

Warner M., Weiss R., 1992. Chlorofluoromethanes in the South Atlantic Antarctic Intermediate Water. Deep-Sea Research, 39, 2053-2075.

Weatherly G.L., Kim Y.Y., Kontar E.A., 2000. Eulerian measurements of the North Atlantic Deep Water Deep Western Boundary Current at $18^{\circ} \mathrm{S}$. Journal of Physical Oceanography, 30, 971-986.

Wienders N., Arhan M., Mercier H., 2000. Circulation at the western boundary of the South and Equatorial Atlantic: Exchanges with the ocean interior. Journal of Marine Research, 58, 1007-1039.

Zemba J., 1991. The structure and transport of the Brazil Current between $27^{\circ} \mathrm{S}$ and $36^{\circ} \mathrm{S}$, Ph.D. thesis, Mass. Inst. of Techn./Woods Hole Oceanogr. Inst., Cambridge, Mass. USA. 


\section{Table and Figures captions:}

Table 1: Numbers of SAMBA float trajectories that crossed the indicated latitude bands, with the associated averaged and minimum/maximum transit times.

Figure 1a: Map of the studied region, with names of the main bathymetric features. Grey scale varies at integer multiples of $500 \mathrm{~m}$.

Figure 1b: SAMBA subsurface float trajectories in the Southwest Atlantic. Most floats drifted between 750 and 900 dbar. Dark red dots indicate the first position for each 2-month (or 3-month) cycle at depth. $800 \mathrm{~m}$ depth outlined white (2000 m and $4000 \mathrm{~m}$ depths black) as in Figure 1a.

Figure 2: Full trajectories of 3 floats $(\mathrm{m} 112, \mathrm{~m} 228, \mathrm{~m} 339)$ that partly drifted in the IWBC. Green dots are the launch positions; dark red dots mark the first positions of all cycles. Some surface positions (red dots) between two consecutive cycles are shown (two or three days surface drifts, as compared to two or three months at depth). One arrow every 30 days. Contoured isobaths are $800 \mathrm{~m}$ (white), $2000 \mathrm{~m}$ and $4000 \mathrm{~m}$.

Figure 3a: SAMBA float velocities (arrows) and temperatures (colour) averaged in $1^{\circ} \times 1^{\circ}$ boxes (minima of 15 days for the temperature and 30 days for the velocity are required). Isobaths at $1000 \mathrm{~m}, 2000 \mathrm{~m}$ and $3000 \mathrm{~m}$. Arrows give the 30-day displacements corresponding to the average velocities. Actually the arrow tails are centred on the barycentre of the float positions within a given $1^{\circ} \times 1^{\circ}$ square.

Figure 3b: Float-inferred Eddy Kinetic Energy (EKE) computed in $1^{\circ} \times 1^{\circ}$ boxes, with at least 30 days of data per box. Isobaths at $1000 \mathrm{~m}, 2000 \mathrm{~m}$ and $3000 \mathrm{~m}$.

Figure 4: a) Definition and sign convention of the angle $\alpha$ between a daily float velocity and the tangent to a reference isobath. b) Scatter plot of the angle between the float velocity and the tangent to the $800 \mathrm{~m}$ isobath at the location closest to the float position, for all float positions inshore of the $3500 \mathrm{~m}$ isobath and north of $27^{\circ} \mathrm{S}$. c) Histogram of the (shortest) float distances to the isobath $800 \mathrm{~m}$ for all float positions inshore of the $3500 \mathrm{~m}$ isobath whose velocities show an angle $|\alpha|<30^{\circ}$ with the tangent to the nearest $800 \mathrm{~m}$ isobath. 
Figure 5: Ensemble of SAMBA float positions found in the IWBC (yellow), and in the intermediate Brazil Current (green), according to the distance and angle criteria given in the text. The float trajectories during the corresponding 3-month measurement cycles are shown in red. $800 \mathrm{~m}$ depth outlined white, $2000 \mathrm{~m}$ and $4000 \mathrm{~m}$ black.

Figure 6: Along-slope distribution of the float positions found in the IWBC (north of $27^{\circ} \mathrm{S}$ for each of the 45 involved floats) and in the intermediate Brazil Current (south of $27^{\circ} \mathrm{S}$ for each of the 16 involved floats). The continuous segments show the continuous trajectory sections (see text). Also displayed is the histogram of the retained positions numbers, drawn using alongshore $100 \mathrm{~km}$ intervals. A graduation in latitude (VTR marks the Vitoria-Trindade Ridge) is coupled with the $27^{\circ} \mathrm{S}$-referenced curvilinear abscissa along the $800 \mathrm{~m}$ isobath.

Figure 7: Alongshore float velocity components at all float positions selected in the Brazil Current and the IWBC, as function of the curvilinear abscissa (positive northward and referenced to $27^{\circ} \mathrm{S}$ ). The averaged velocity in $100 \mathrm{~km}$ intervals (continuous), the associated standard deviations (dashed), and 10 historical estimates of the boundary flow velocities (see text and references below) are also displayed. The histogram gives the number of float positions in $100 \mathrm{~km}$ intervals. The curvilinear distance graduation is coupled with a latitude graduation. Current data from Müller et al., 1998 (๑), Da Silveira et al., 2004 \& 2008 (+), Schott at al., 2005 (×), Stramma et al., 1995 (ロ) and Schott at al., $2002(\Delta)$.

Figure 8: Upper: Alongshore float velocity components as function of the distance to the 800 $\mathrm{m}$ isobath, in the three latitudinal bands $27^{\circ} \mathrm{S}-20^{\circ} \mathrm{S}, 20^{\circ} \mathrm{S}-15^{\circ} \mathrm{S}$ and $15^{\circ} \mathrm{S}-5^{\circ} \mathrm{S}$. Superimposed are the averaged velocities (continuous) and the plus/minus one standard deviation curves (dashed) in $5 \mathrm{~km}$ intervals. Middle: Numbers of selected positions per $5 \mathrm{~km}$ intervals. Lower: Averaged continental slope profiles in each latitudinal band (continuous). The bathymetric profiles across the Santos Plateau (at $24^{\circ} \mathrm{S}$ ) and the Recife Plateau (at $8^{\circ} 12^{\prime} \mathrm{S}$ ) are also shown (dashed) in the southern and northern zone panels.

Figure 9: Float positions selected in the poleward intermediate counter current between $15^{\circ} \mathrm{S}$ and $5^{\circ} \mathrm{S}$ (red) with the 90-day long upstream (a,b) and downstream (c,d) trajectory sections (yellow and orange respectively). The four panels distinguish the counter 
current inputs from the IWBC (a) and ocean interior (b), and the counter current outputs to the IWBC (c) and ocean interior (d).

Figure 10: Float positions selected in the poleward intermediate counter current between $27^{\circ} \mathrm{S}$ and $20^{\circ} \mathrm{S}$ (red) with the 150-day long upstream (a,b) and downstream (c,d) trajectory sections (yellow and orange respectively). The four panels distinguish the counter current inputs from the IWBC (a) and ocean interior (b), and the counter current outputs to the IWBC (c) and ocean interior (d).

Figure 11a: Trajectories of the floats that marked the Santos bifurcation, distinguishing those that eventually bifurcated southward (blue) and northward (green). The few magenta trajectories correspond to float immersions greater than 1050 dbar. Only the floats that happened to be in the western boundary during their lives are shown here. Crosses mark the first positions of every 2-month (or 3-month) cycles.

Figure 11b: Averaged float velocities in $1^{\circ} \times 1^{\circ}$ boxes given as equivalent displacements over 30 days (blue arrows correspond to averaged velocities less than $5 \mathrm{~cm} \mathrm{~s}^{-1}$, yellow arrows to averaged velocities greater than $5 \mathrm{~cm} \mathrm{~s}^{-1}$ ). Averaged velocities were estimated with at least 30 days of data per box and the arrow bases are located at the barycentres of the float positions found within the given boxes. More than $99 \%$ of the data is comprised between 650 and $1050 \mathrm{dbar}$, and 93\% is comprised between 775 and 875 dbar. The thick red arrows show averaged velocities from current meter measurements (Müller et al., 1998; Hogg et al., 1999). Black dots mark the stations of the WOCE/A17 hydrographic section used for transport computations, and the dashed rectangle is where averaged transports were also computed (see text). Contoured isobaths are $800 \mathrm{~m}$ (white), $2000 \mathrm{~m}$ and $4000 \mathrm{~m}$.

Figure 12: Trajectories of the floats that sampled the region west of $36^{\circ} \mathrm{W}$, between $20^{\circ} \mathrm{S}$ and $16^{\circ} \mathrm{S}$. The colours distinguish the floats that drifted along the continental slope between $20^{\circ} \mathrm{S}$ and $18^{\circ} \mathrm{S}$ totally (yellow) or partially (red), or that remained offshore (blue). Two floats managed to pass into a very narrow and shallow channel cutting through the Abrolhos bank (green trajectories). Dotted lines give the overall displacements between two positions, when some intermediate daily positions are lacking. One arrow every 30 days. Contoured isobaths are $800 \mathrm{~m}$ (white), $2000 \mathrm{~m}$ and $4000 \mathrm{~m}$. 
Figure 13: Float trajectories at the transition latitudes between the domain of irregular continental slope and poorly-defined IWBC at $18^{\circ} \mathrm{S}-15^{\circ} \mathrm{S}$, and the region of welldefined boundary flow north of $15^{\circ} \mathrm{S}$. Different colours indicate different float behaviours. One arrow every 30 days. Contoured isobaths are $800 \mathrm{~m}$ (white), $2000 \mathrm{~m}$ and $4000 \mathrm{~m}$.

Figure 14: Percentages of float entries in the IWBC (green), float escapes from the IWBC (red), and float along-slope drifts in the boundary flow (blue), as function of curvilinear distance. The fractions are computed in $1^{\circ}$ latitude intervals, except around the inshore passage through VTR. Entries into (and escapes from) the boundary current are defined as the southern (northern) ends of the boundary flow continuous segments shown in Figure 6. Blue vertical bars give the numbers of floats in the $1^{\circ}$ latitude intervals. Latitudinal distribution of the curvature of the smoothed $800 \mathrm{~m}$ isobath is shown at the bottom. Major capes and bathymetric features are: cape Frio (CF), cape São Tomé (CST), Vitoria-Trindade ridge (VTR), Abrolhos Bank (AB), Royal Charlotte bank (RCB), Recife Plateau (RP), and cape São Roque (CSR).

Figure 15: Float trajectories along the continental slope between $13^{\circ} \mathrm{S}$ and $5^{\circ} \mathrm{S}$, illustrating the weak number of entries in the IWBC (green) and large number of exits (other colours) in that region. The yellow trajectories show the floats that remained in the IWBC. One arrow every 30 days. Contoured isobaths are $800 \mathrm{~m}$ (white), $2000 \mathrm{~m}$ and $4000 \mathrm{~m}$.

\begin{tabular}{cccc}
\hline Meridional zone & Number of trajectories & $\begin{array}{c}\text { Averaged transit time } \\
\text { (days) }\end{array}$ & $\begin{array}{c}\text { Minimum/maximum } \\
\text { Transit time (days) }\end{array}$ \\
\hline $24^{\circ} \mathrm{S}-20^{\circ} 30^{\prime} \mathrm{S}$ & 11 & $42 \pm 12$ & $28 / 62$ \\
$20^{\circ} \mathrm{S}-16^{\circ} \mathrm{S}$ & 13 & $201 \pm 270$ & $29 / 1000$ \\
$1^{\circ} \mathrm{S}-5^{\circ} \mathrm{S}$ & 4 & $72 \pm 5$ & $67 / 78$ \\
$5^{\circ} \mathrm{S}-0^{\circ} \mathrm{S}$ & 1 & 112 & $112 / 112$ \\
$23^{\circ} 30^{\prime} \mathrm{S}-5^{\circ} \mathrm{S}$ & 3 & $365 \pm 68$ & $307 / 440$ \\
\hline
\end{tabular}

Table 1: Numbers of SAMBA float trajectories that crossed the indicated latitude bands, with the associated averaged and minimum/maximum transit times. 


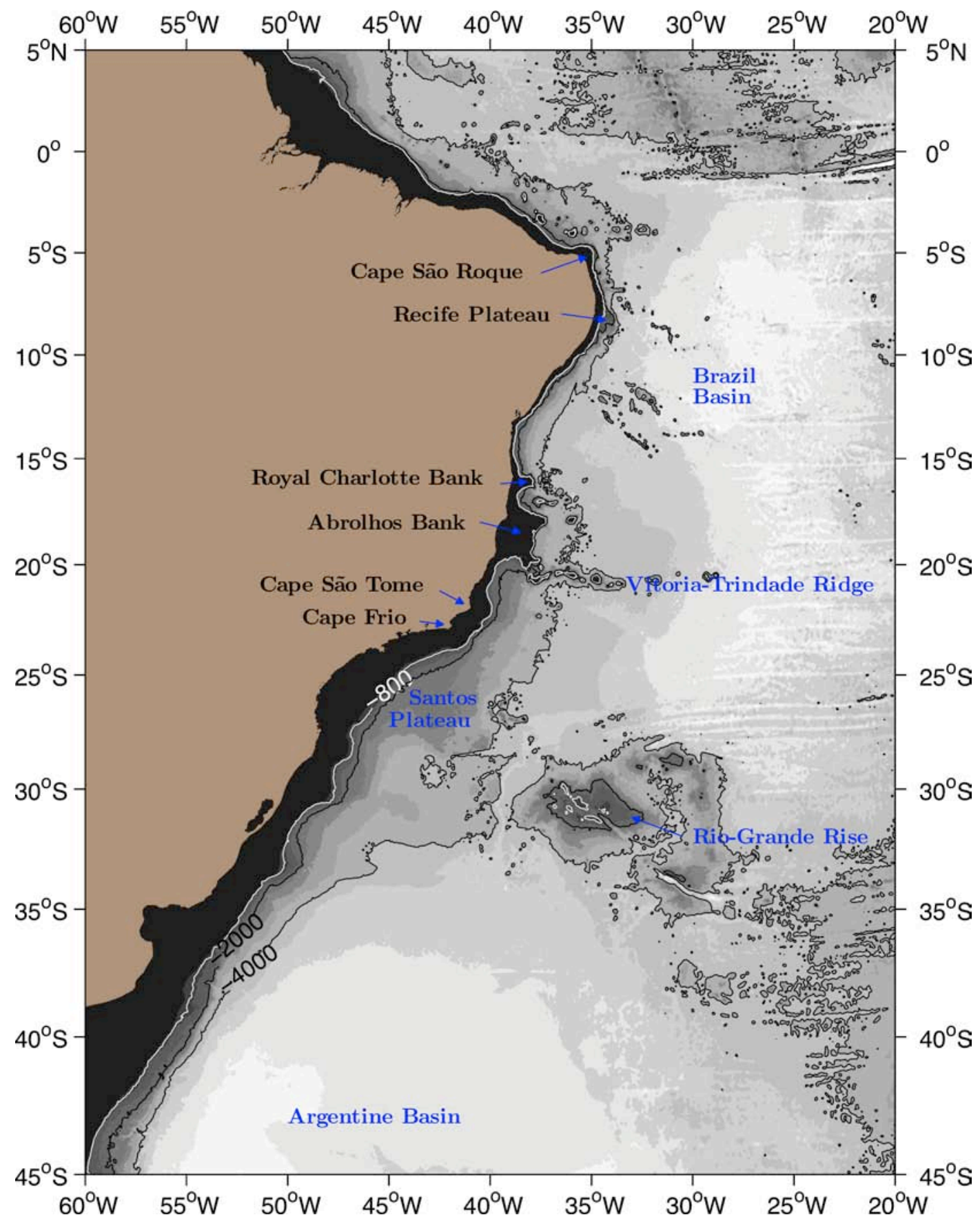

Figure 1a: Map of the studied region, with names of the main bathymetric features. Grey scale varies at integer multiples of $500 \mathrm{~m}$. 


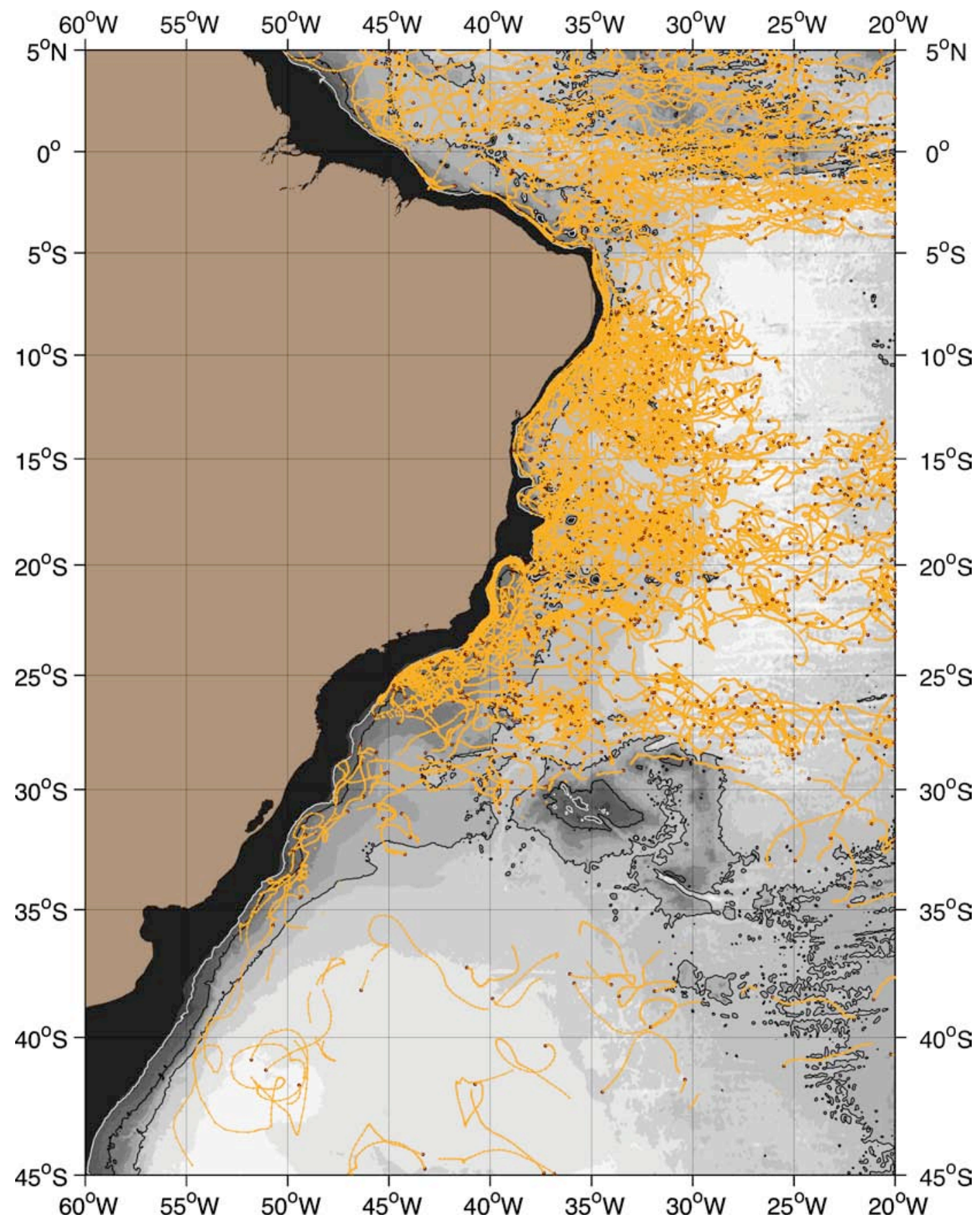

Figure 1b: SAMBA subsurface float trajectories in the Southwest Atlantic. Most floats drifted between 750 and 900 dbar. Dark red dots indicate the first position for each 2-month (or 3month) cycle at depth. $800 \mathrm{~m}$ depth outlined white (2000 m and $4000 \mathrm{~m}$ depths black) as in Figure 1a. 


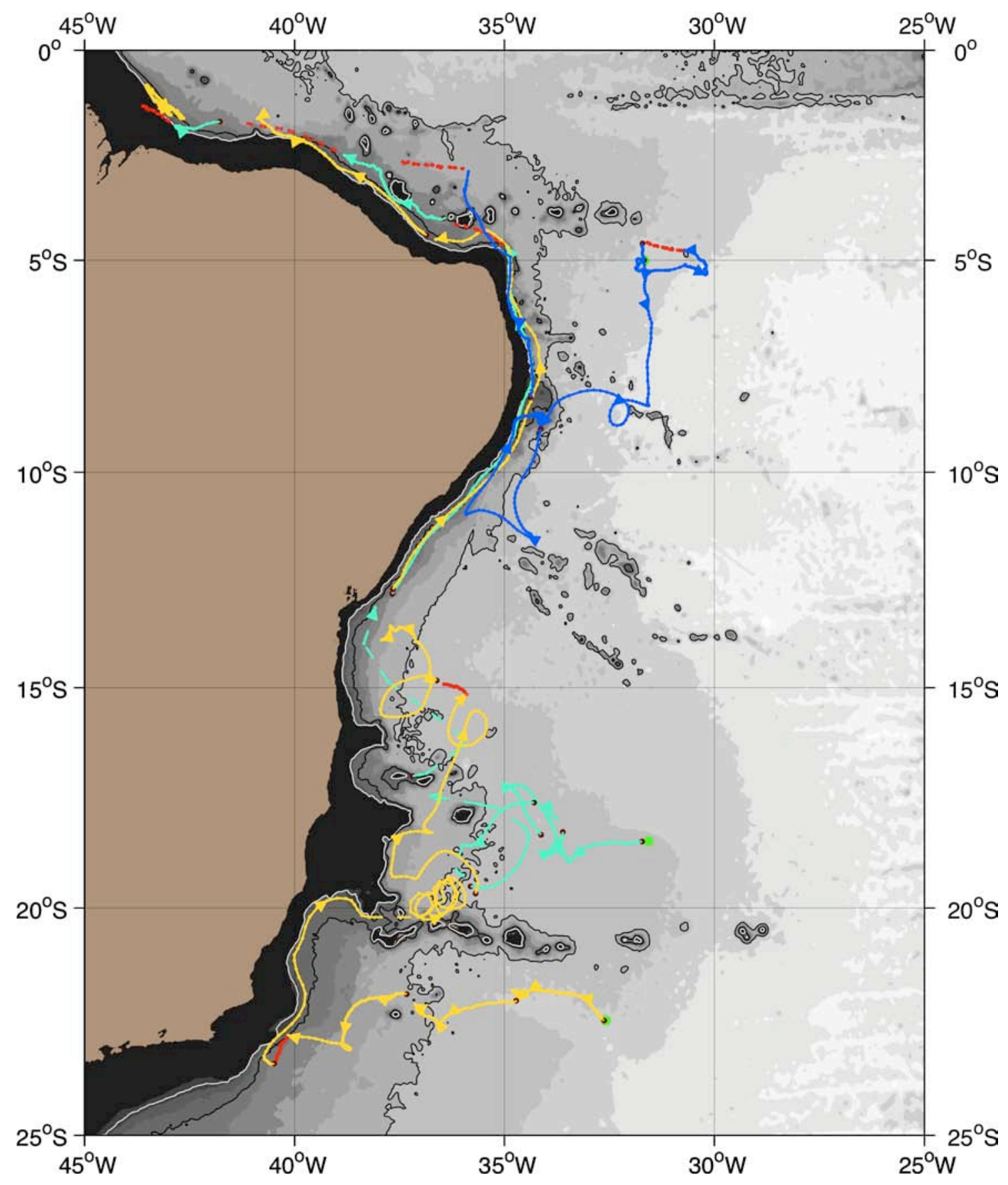

Figure 2: Full trajectories of 3 floats $(\mathrm{m} 112, \mathrm{~m} 228, \mathrm{~m} 339)$ that partly drifted in the IWBC. Green dots are the launch positions; dark red dots mark the first positions of all cycles. Some surface positions (red dots) between two consecutive cycles are shown (two or three days surface drifts, as compared to two or three months at depth). One arrow every 30 days. Contoured isobaths are $800 \mathrm{~m}$ (white), $2000 \mathrm{~m}$ and $4000 \mathrm{~m}$. 


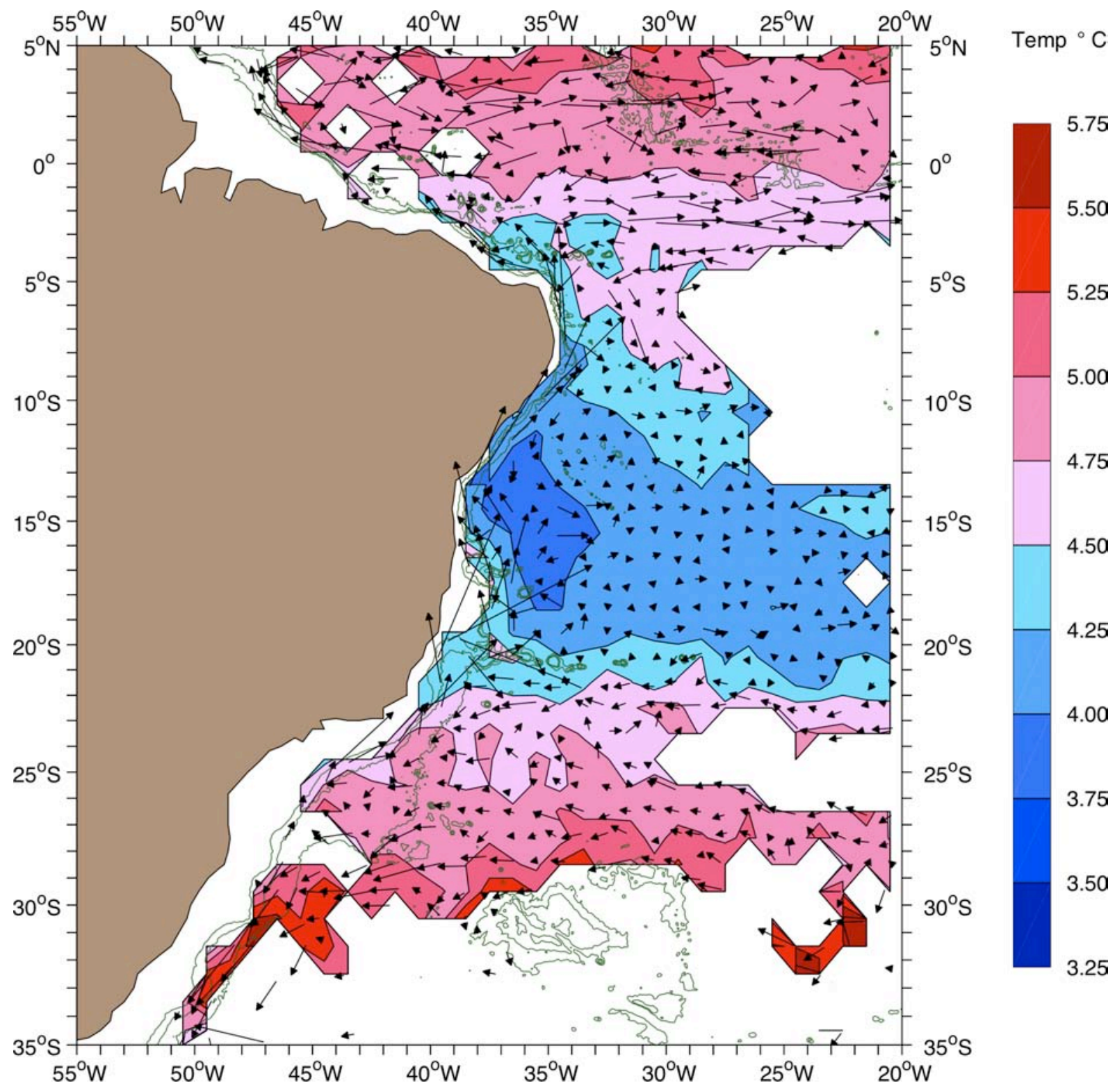

Figure 3a: SAMBA float velocities (arrows) and temperatures (colour) averaged in $1{ }^{\circ} \times 1^{\circ}$ boxes (minima of 15 days for the temperature and 30 days for the velocity are required). Isobaths at $1000 \mathrm{~m}, 2000 \mathrm{~m}$ and $3000 \mathrm{~m}$. Arrows give the 30 -day displacements corresponding to the averaged velocities. Actually the arrow tails are centred on the barycentre of the float positions within a given $1^{\circ} \times 1^{\circ}$ square. 


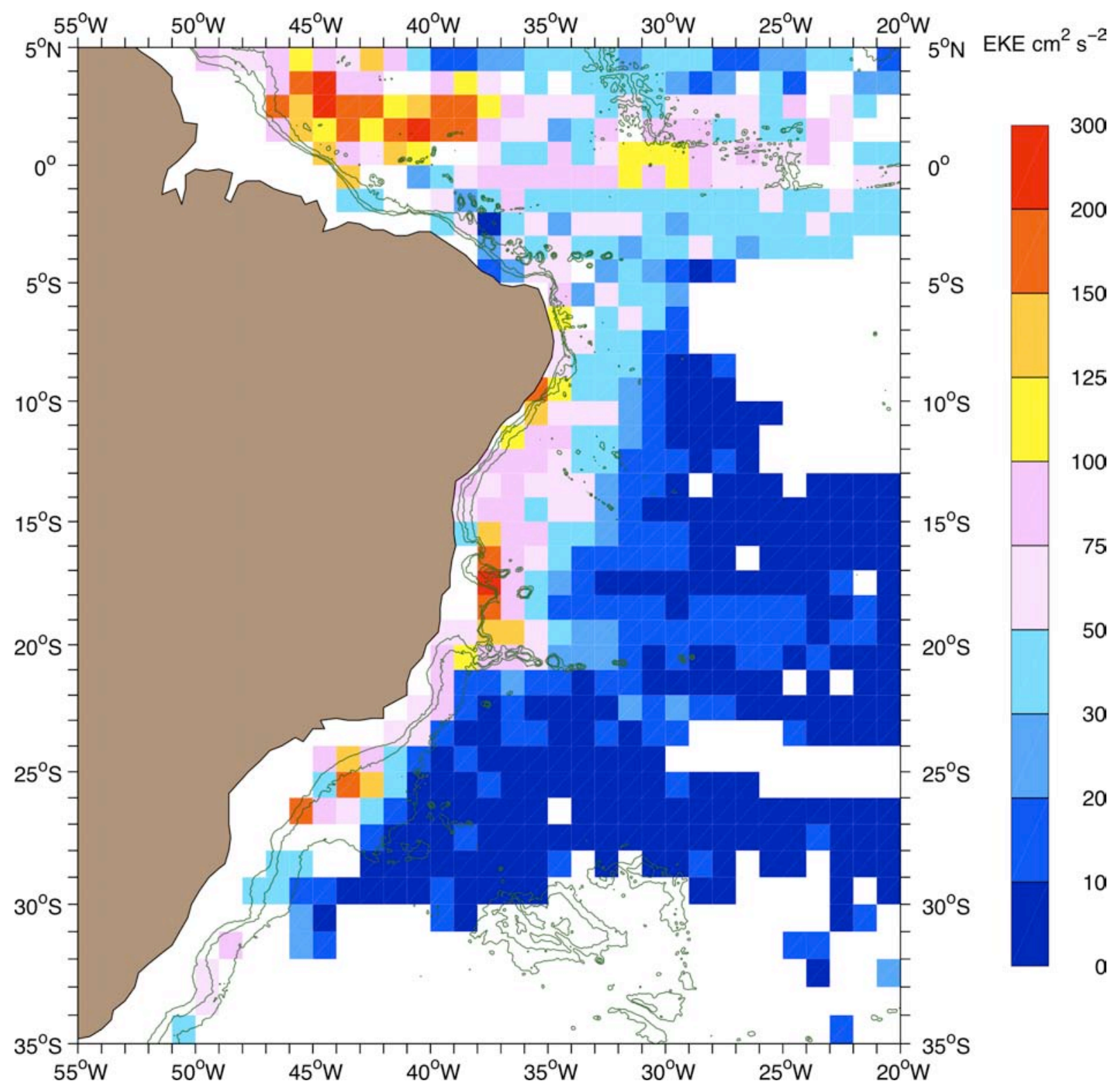

Figure 3b Float-inferred Eddy Kinetic Energy (EKE) computed in $1^{\circ} \mathrm{x} 1^{\circ}$ boxes, with at least 30 days of data per box. Isobaths at $1000 \mathrm{~m}, 2000 \mathrm{~m}$ and $3000 \mathrm{~m}$. 
a

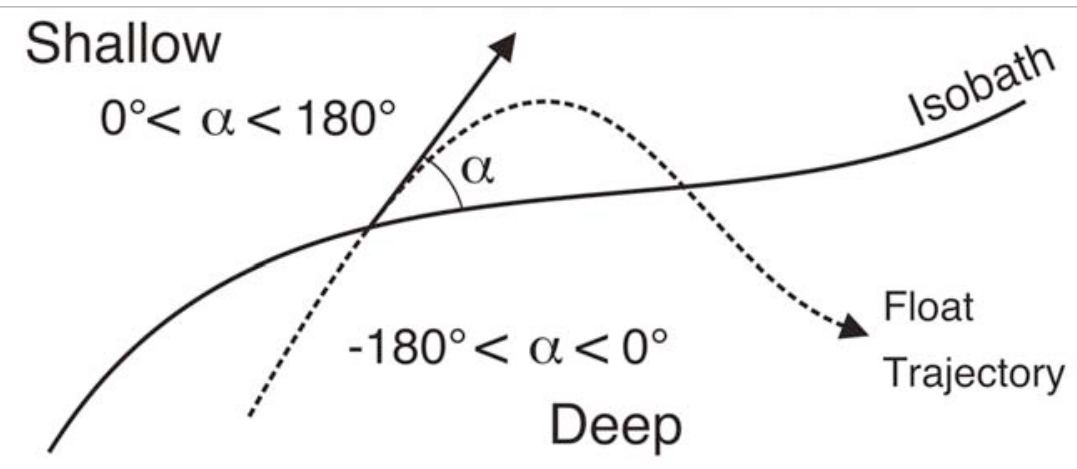

b

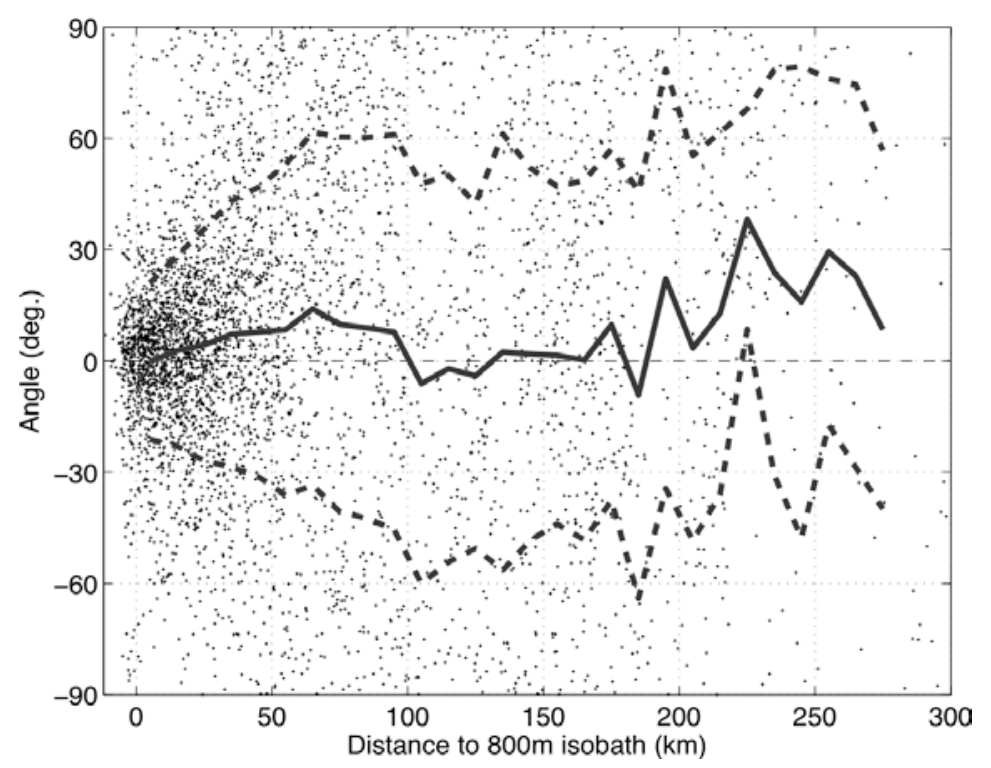

C

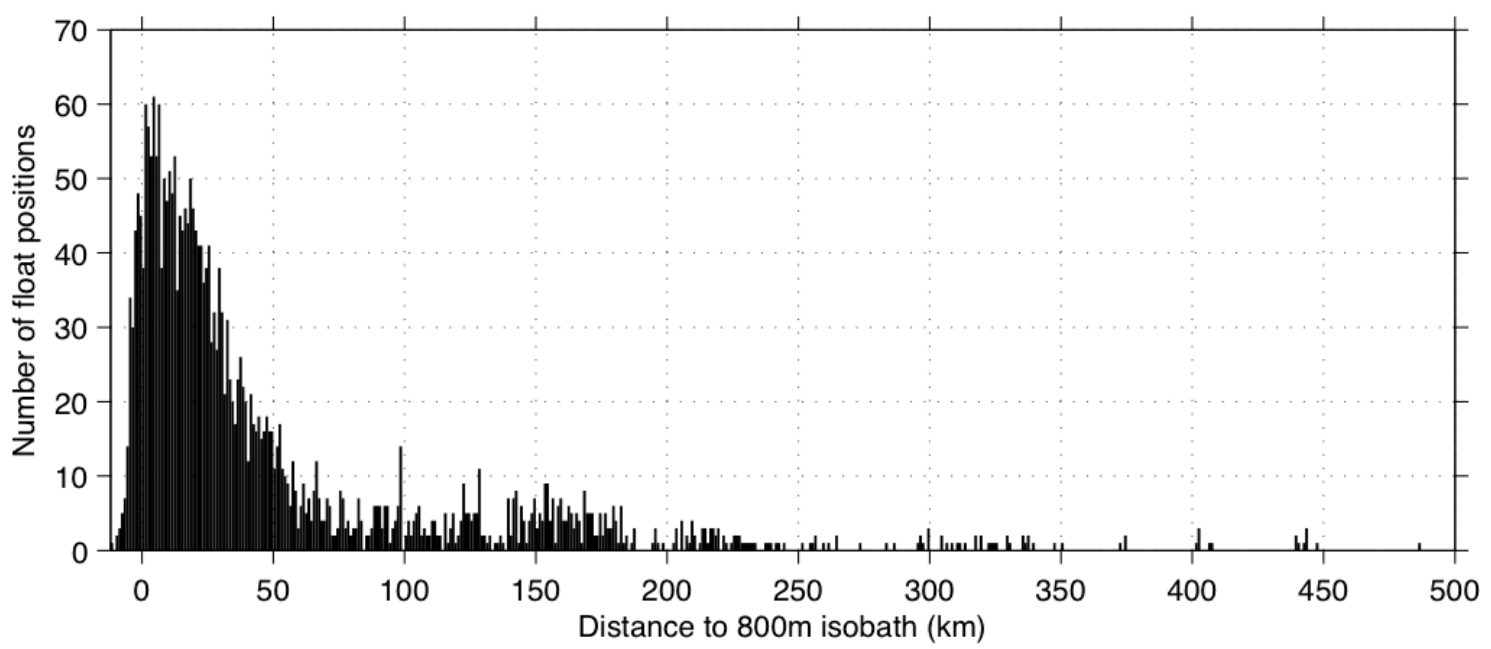

Figure 4: a) Definition and sign convention of the angle $\alpha$ between a daily float velocity and the tangent to a reference isobath. b) Scatter plot of the angle between the float velocity and the tangent to the $800 \mathrm{~m}$ isobath at the location closest to the float position, for all float positions inshore of the $3500 \mathrm{~m}$ isobath and north of $27^{\circ} \mathrm{S}$. c) Histogram of the (shortest) float distances to the isobath $800 \mathrm{~m}$ for all float positions inshore of the $3500 \mathrm{~m}$ isobath whose velocities show an angle $|\alpha|<30^{\circ}$ with the tangent to the nearest $800 \mathrm{~m}$ isobath. 


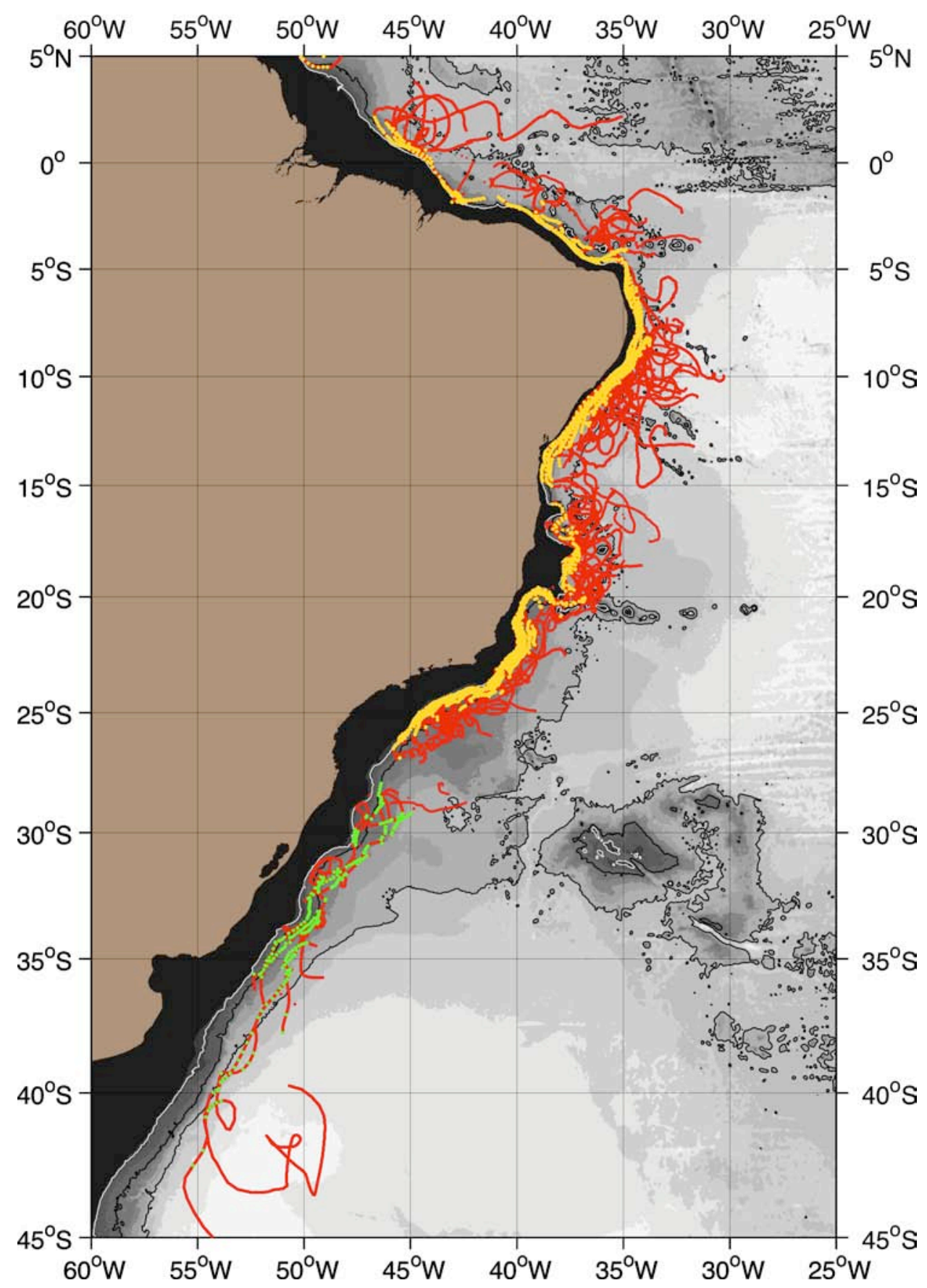

Figure 5: Ensemble of SAMBA float positions found in the IWBC (yellow), and in the intermediate Brazil Current (green), according to the distance and angle criteria given in the text. The float trajectories during the corresponding 3-month measurement cycles are shown in red. $800 \mathrm{~m}$ depth outlined white, $2000 \mathrm{~m}$ and $4000 \mathrm{~m}$ black. 


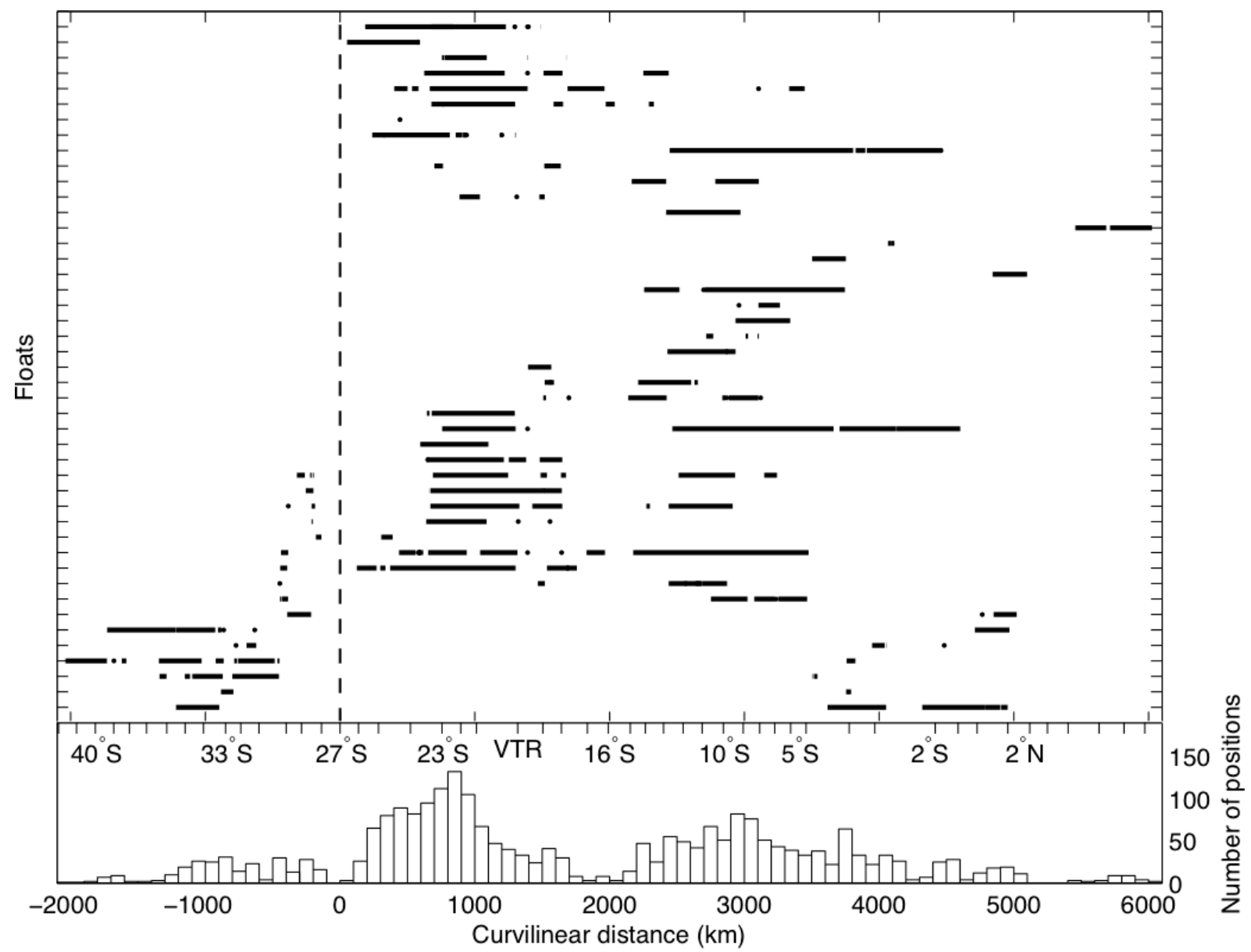

Figure 6: Along-slope distribution of the float positions found in the IWBC (north of $27^{\circ} \mathrm{S}$ for each of the 45 involved floats) and in the intermediate Brazil Current (south of $27^{\circ} \mathrm{S}$ for each of the 16 involved floats). The continuous segments show the continuous trajectory sections (see text). Also displayed is the histogram of the retained positions numbers, drawn using alongshore $100 \mathrm{~km}$ intervals. A graduation in latitude (VTR marks the Vitoria-Trindade Ridge) is coupled with the $27^{\circ} \mathrm{S}$-referenced curvilinear abscissa along the $800 \mathrm{~m}$ isobath. 


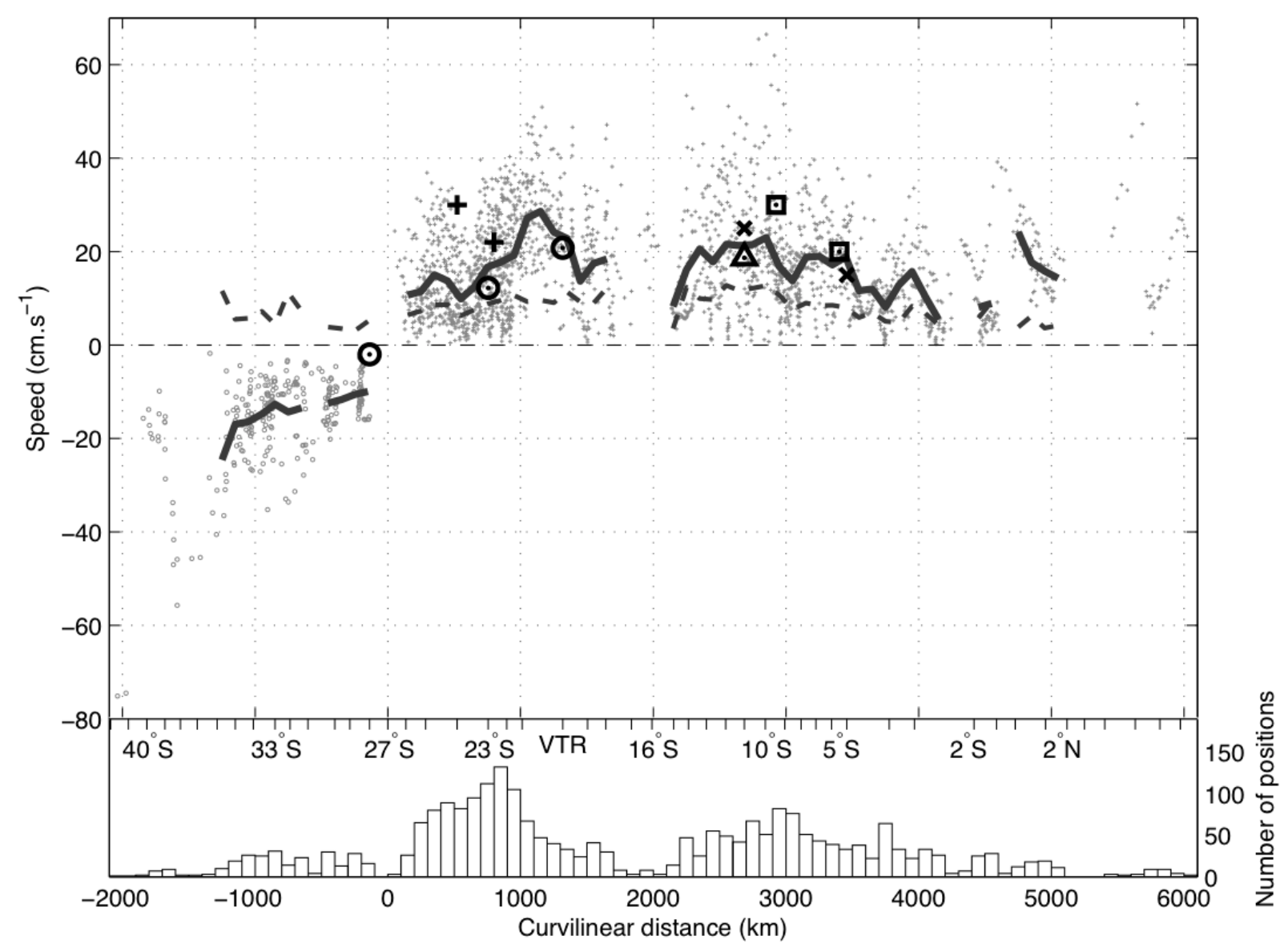

Figure 7: Alongshore float velocity components at all float positions selected in the Brazil Current and the IWBC, as function of the curvilinear abscissa (positive northward and referenced to $27^{\circ} \mathrm{S}$ ). The averaged velocity in $100 \mathrm{~km}$ intervals (continuous), the associated standard deviations (dashed), and 10 historical estimates of the boundary flow velocities (see text and references below) are also displayed. The histogram gives the number of float positions in $100 \mathrm{~km}$ intervals. The curvilinear distance graduation is coupled with a latitude graduation. Current data from Müller et al., 1998 (๑), Da Silveira et al., 2004 \& $2008(+)$, Schott at al., $2005(\times)$, Stramma et al., $1995(\square)$ and Schott at al., $2002(\Delta)$. 

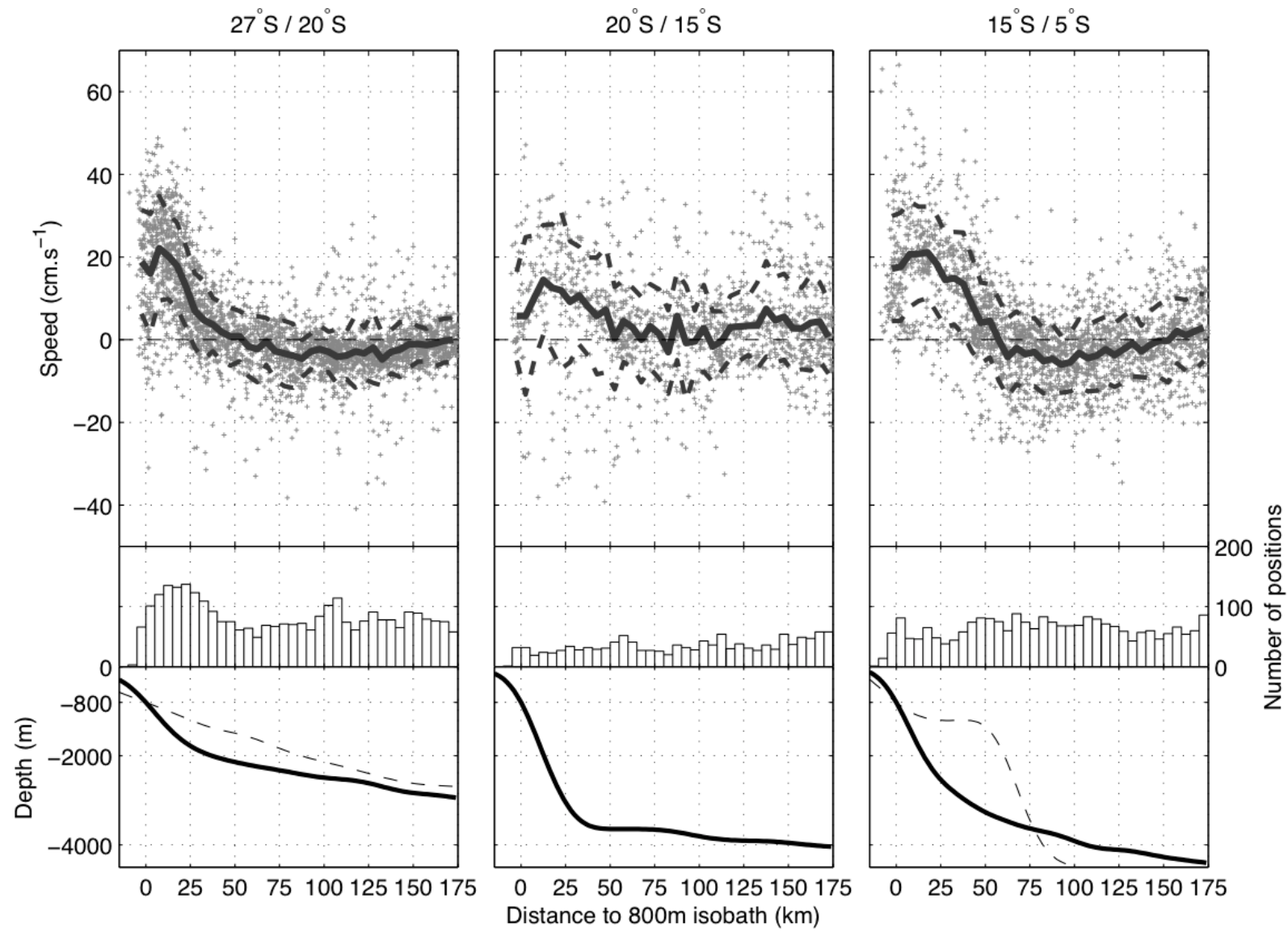

Figure 8: Upper: Alongshore float velocity components as function of the distance to the 800 $\mathrm{m}$ isobath, in the three latitudinal bands $27^{\circ} \mathrm{S}-20^{\circ} \mathrm{S}, 20^{\circ} \mathrm{S}-15^{\circ} \mathrm{S}$ and $15^{\circ} \mathrm{S}-5^{\circ} \mathrm{S}$. Superimposed are the averaged velocities (continuous) and the plus/minus one standard deviation curves (dashed) in $5 \mathrm{~km}$ intervals. Middle: Numbers of selected positions per $5 \mathrm{~km}$ intervals. Lower: Averaged continental slope profiles in each latitudinal band (continuous). The bathymetric profiles across the Santos Plateau (at $24^{\circ} \mathrm{S}$ ) and the Recife Plateau (at $8^{\circ} 12^{\prime} \mathrm{S}$ ) are also shown (dashed) in the southern and northern zone panels. 

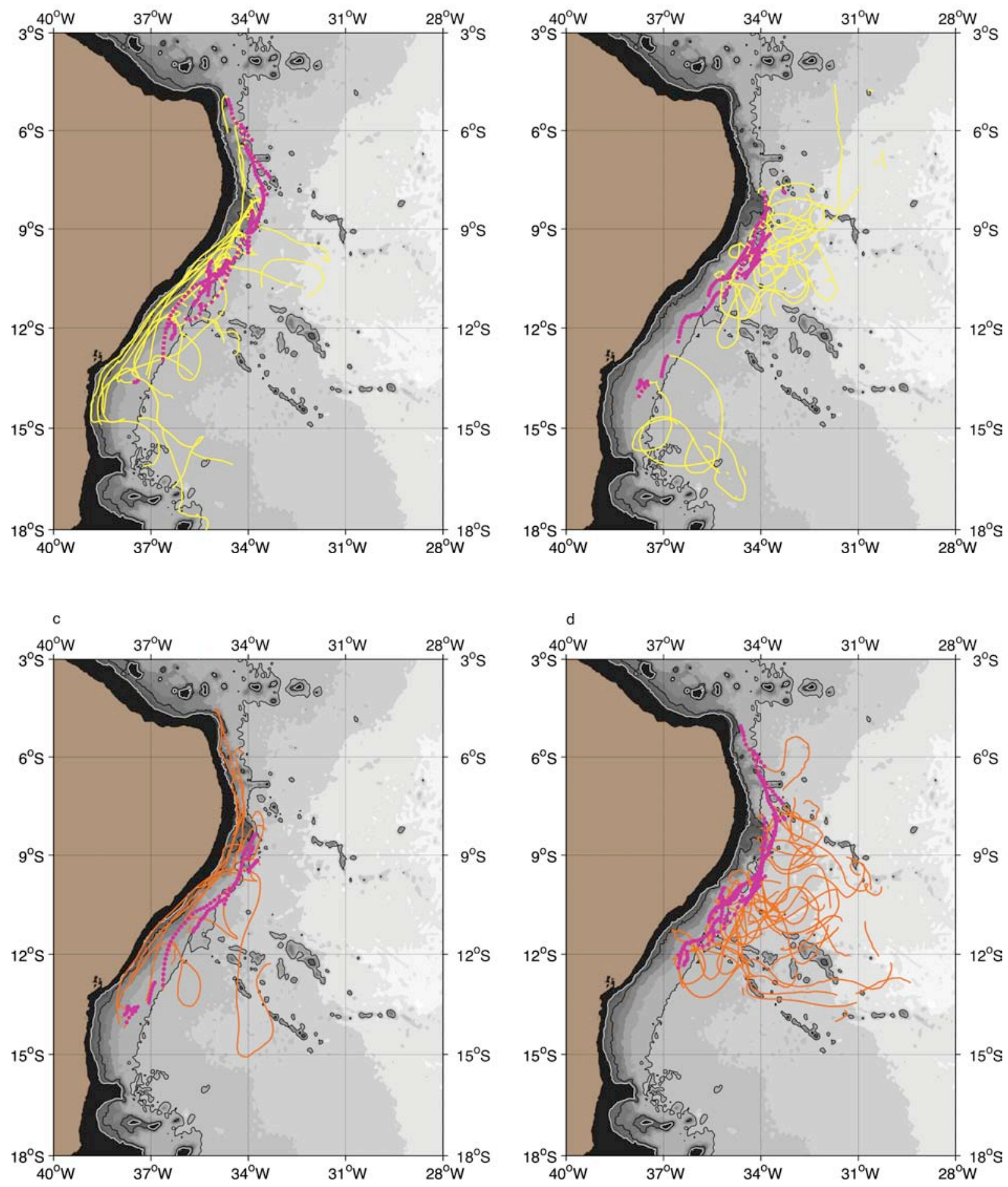

Figure 9: Float positions selected in the poleward intermediate counter current between $15^{\circ} \mathrm{S}$ and $5^{\circ} \mathrm{S}$ (magenta) with the 90-day long upstream (a, b) and downstream (c, d) trajectory sections (yellow and orange respectively). The four panels distinguish the counter current inputs from the IWBC (a) and ocean interior (b), and the counter current outputs to the IWBC (c) and ocean interior $(\mathrm{d})$. 

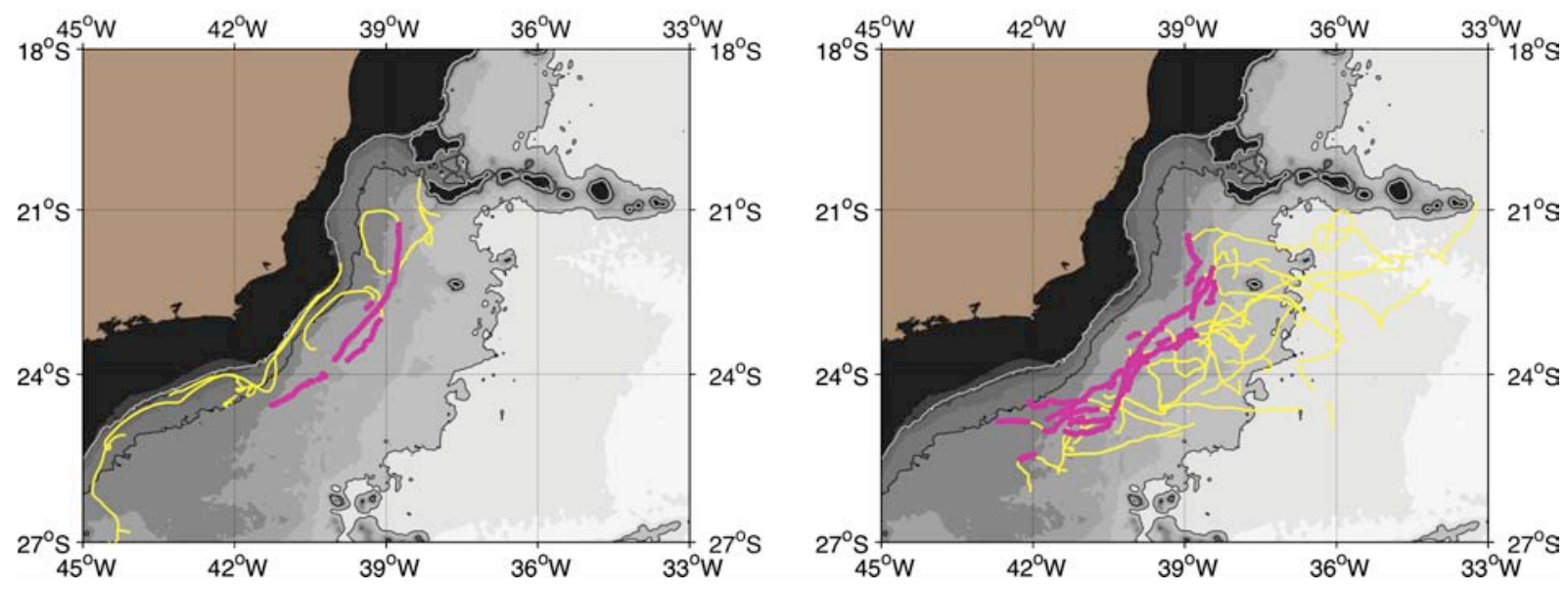

C

d
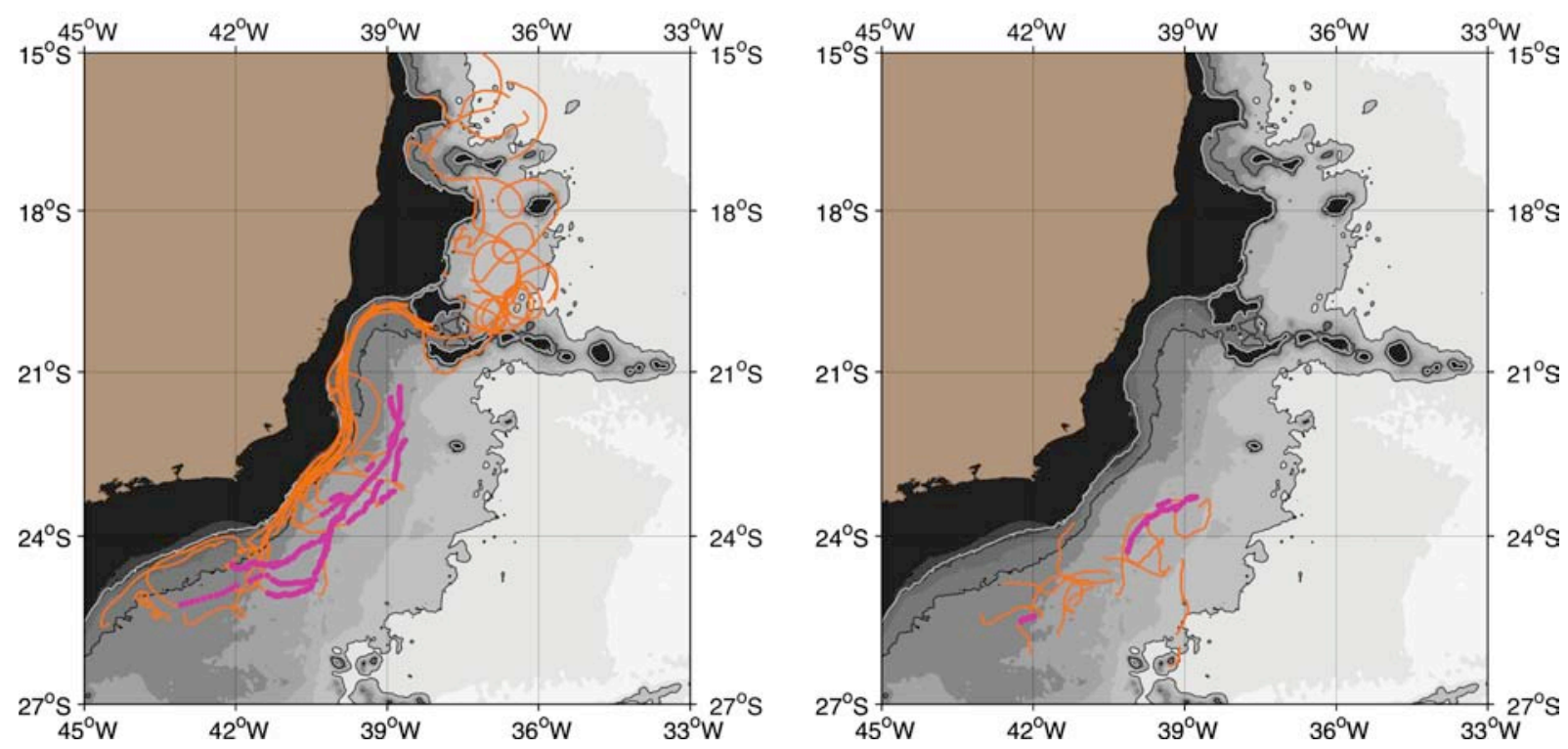

Figure 10: Float positions selected in the poleward intermediate counter current between $27^{\circ} \mathrm{S}$ and $20^{\circ} \mathrm{S}$ (magenta) with the 150-day long upstream (a,b) and downstream (c,d) trajectory sections (yellow and orange respectively). The four panels distinguish the counter current inputs from the IWBC (a) and ocean interior (b), and the counter current outputs to the IWBC (c) and ocean interior $(d)$. 


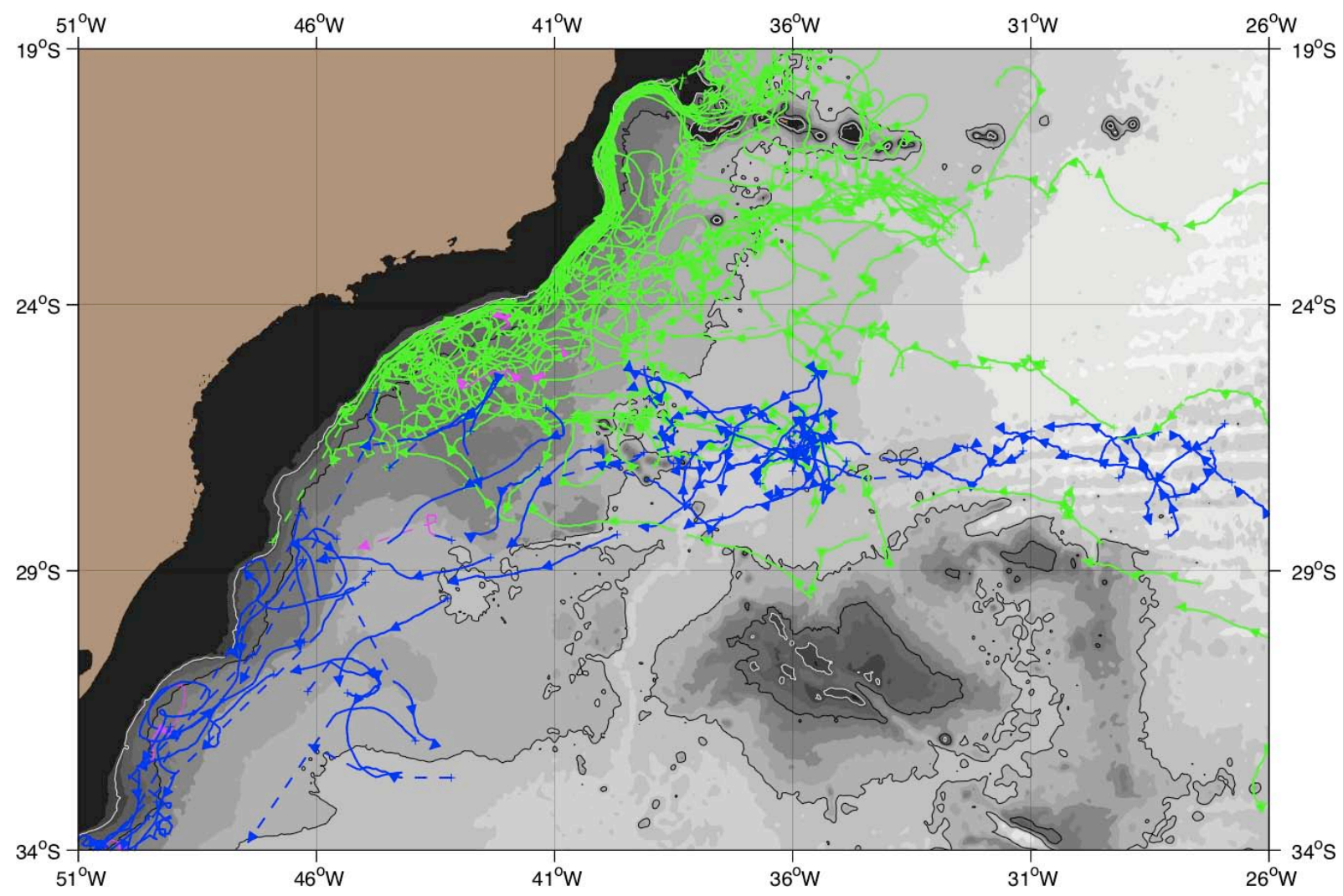

Figure 11 a) Trajectories of the floats that marked the Santos bifurcation, distinguishing those that eventually bifurcated southward (blue) and northward (green). The few magenta trajectories correspond to float immersions greater than 1050 dbar. Only the floats that happened to be in the western boundary during their lives are shown here. Crosses mark the first positions for every 2-month (or 3-month) cycles. 


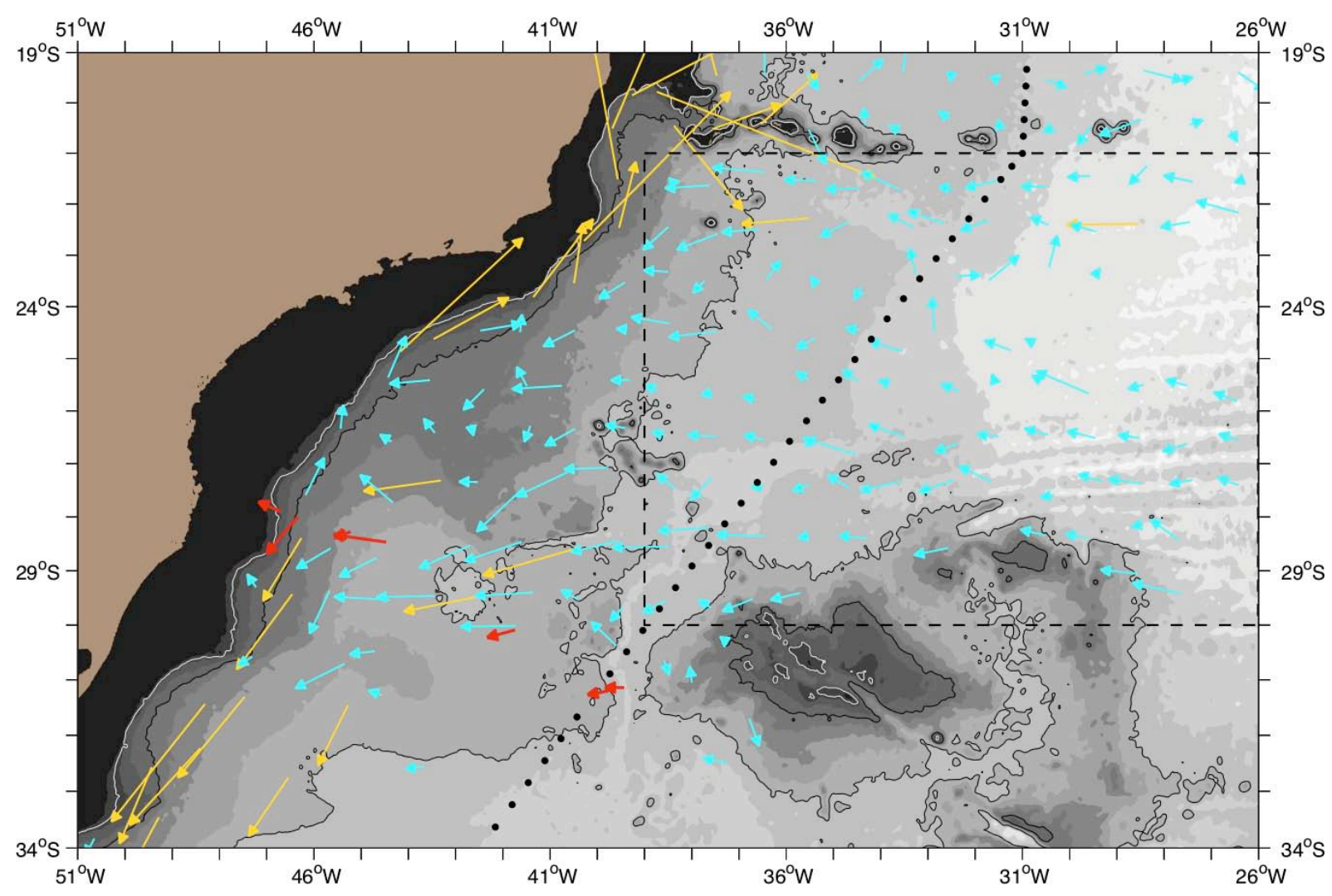

Figure $11 \mathrm{~b}$ ) Averaged float velocities in $1^{\circ} \times 1^{\circ}$ boxes given as equivalent displacements over 30 days (blue arrows correspond to averaged velocities less than $5 \mathrm{~cm} \mathrm{~s}^{-1}$, yellow arrows to averaged velocities greater than $5 \mathrm{~cm} \mathrm{~s}^{-1}$ ). Averaged velocities were estimated with at least 30 days of data per box and the arrow bases are located at the barycentres of the float positions found within the given boxes. More than $99 \%$ of the data is comprised between 650 and 1050 dbar, and $93 \%$ is comprised between 775 and 875 dbar.

The thick red arrows show averaged velocities from current meter measurements (Müller et al., 1998; Hogg et al., 1999). Black dots mark the stations of the WOCE/A17 hydrographic section used for transport computations, and the dashed rectangle is where averaged transports were also computed (see text). Contoured isobaths are $800 \mathrm{~m}$ (white), $2000 \mathrm{~m}$ and $4000 \mathrm{~m}$. 


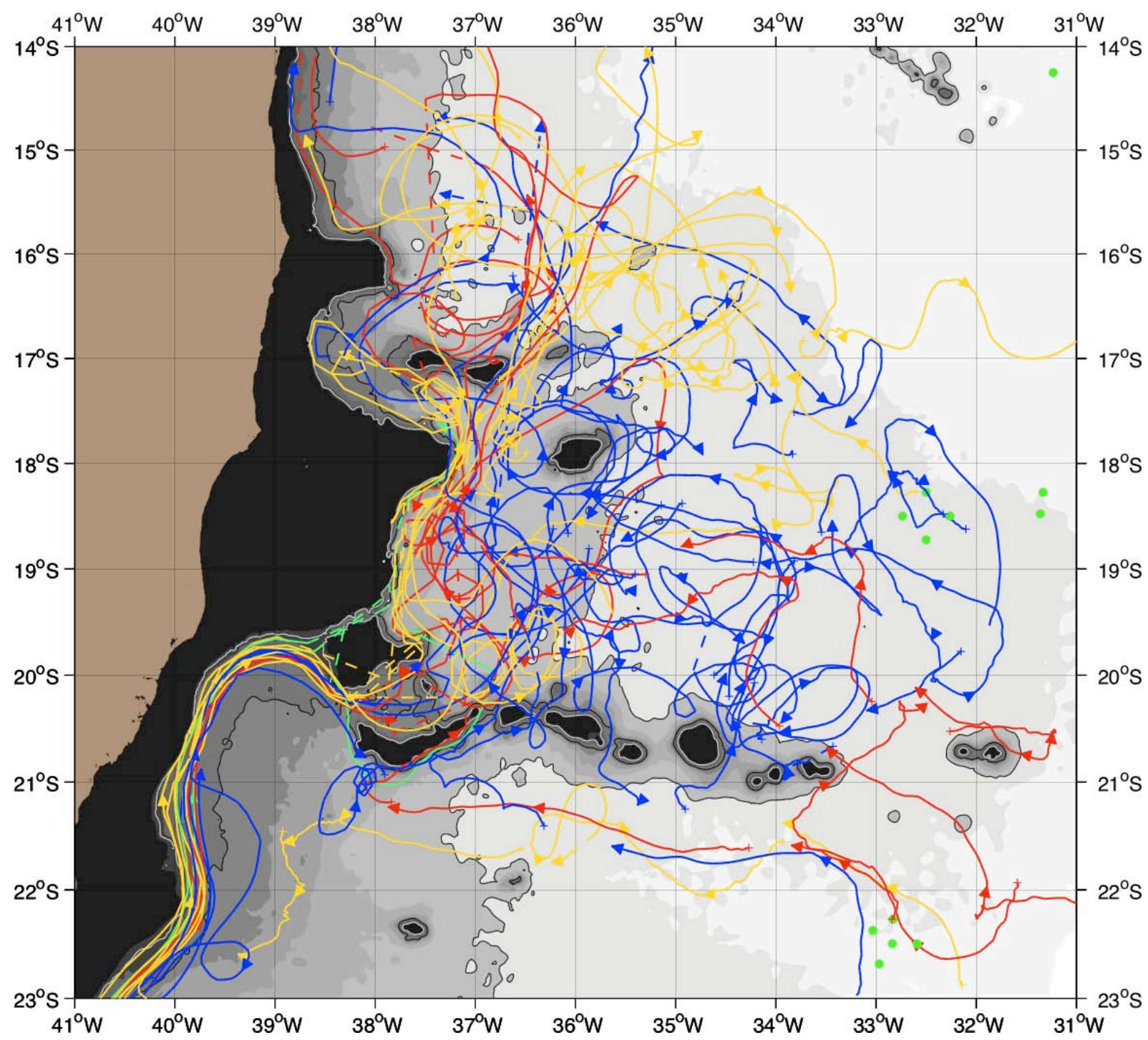

Figure 12: Trajectories of the floats that sampled the region west of $36^{\circ} \mathrm{W}$, between $20^{\circ} \mathrm{S}$ and $16^{\circ} \mathrm{S}$. The colours distinguish the floats that drifted along the continental slope between $20^{\circ} \mathrm{S}$ and $18^{\circ} \mathrm{S}$ totally (yellow) or partially (red), or that remained offshore (blue). Two floats managed to pass into a very narrow and shallow channel cutting through the Abrolhos bank (green trajectories). Dotted lines give the overall displacements between two positions, when some intermediate daily positions are lacking. One arrow every 30 days. Contoured isobaths are $800 \mathrm{~m}$ (white), $2000 \mathrm{~m}$ and $4000 \mathrm{~m}$. 


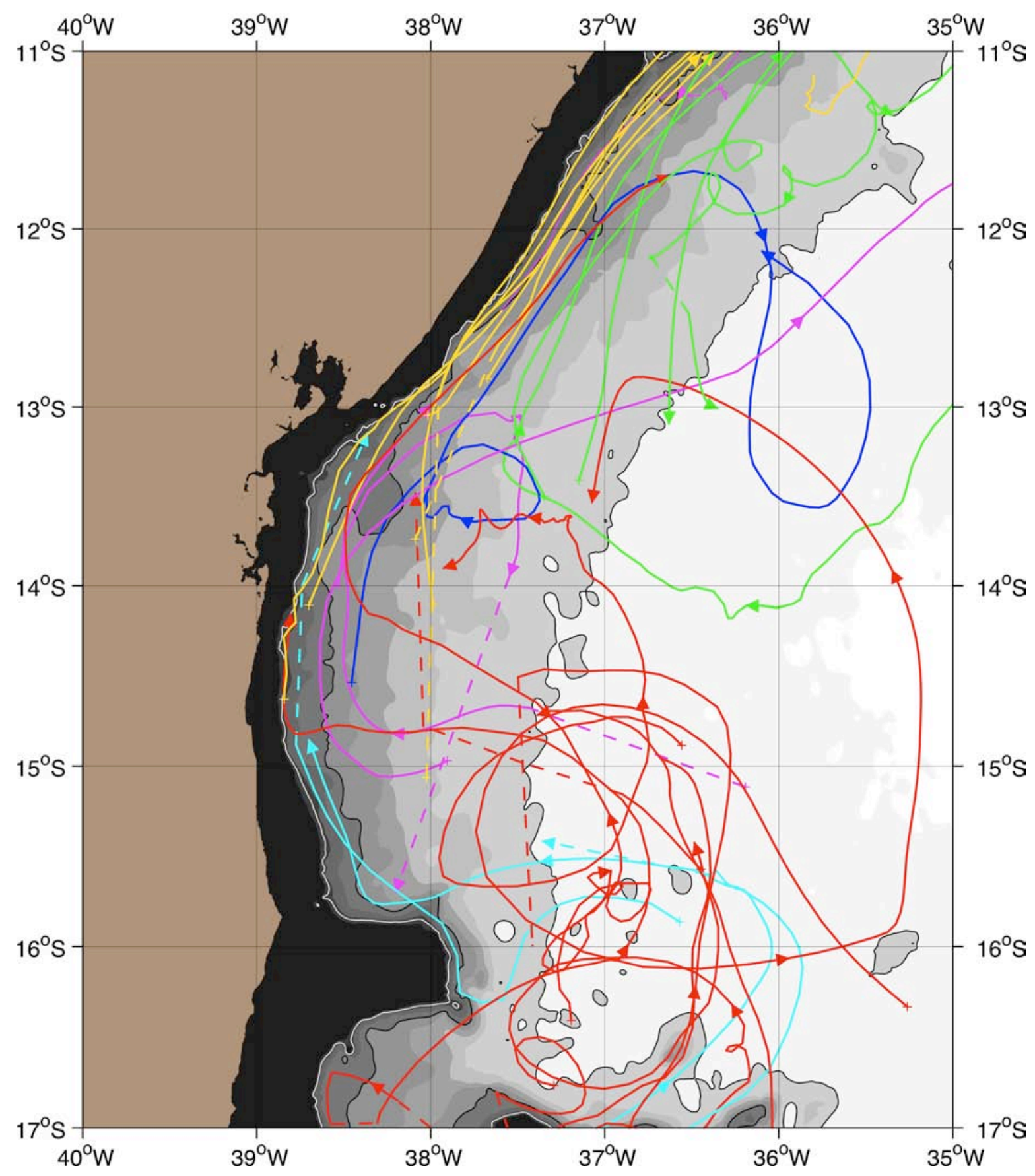

Figure 13: Float trajectories at the transition latitudes between the domain of irregular continental slope and poorly-defined IWBC at $18^{\circ} \mathrm{S}-15^{\circ} \mathrm{S}$, and the region of well-defined boundary flow north of $15^{\circ} \mathrm{S}$. Different colours indicate different float behaviours. One arrow every 30 days. Contoured isobaths are $800 \mathrm{~m}$ (white), $2000 \mathrm{~m}$ and $4000 \mathrm{~m}$. 

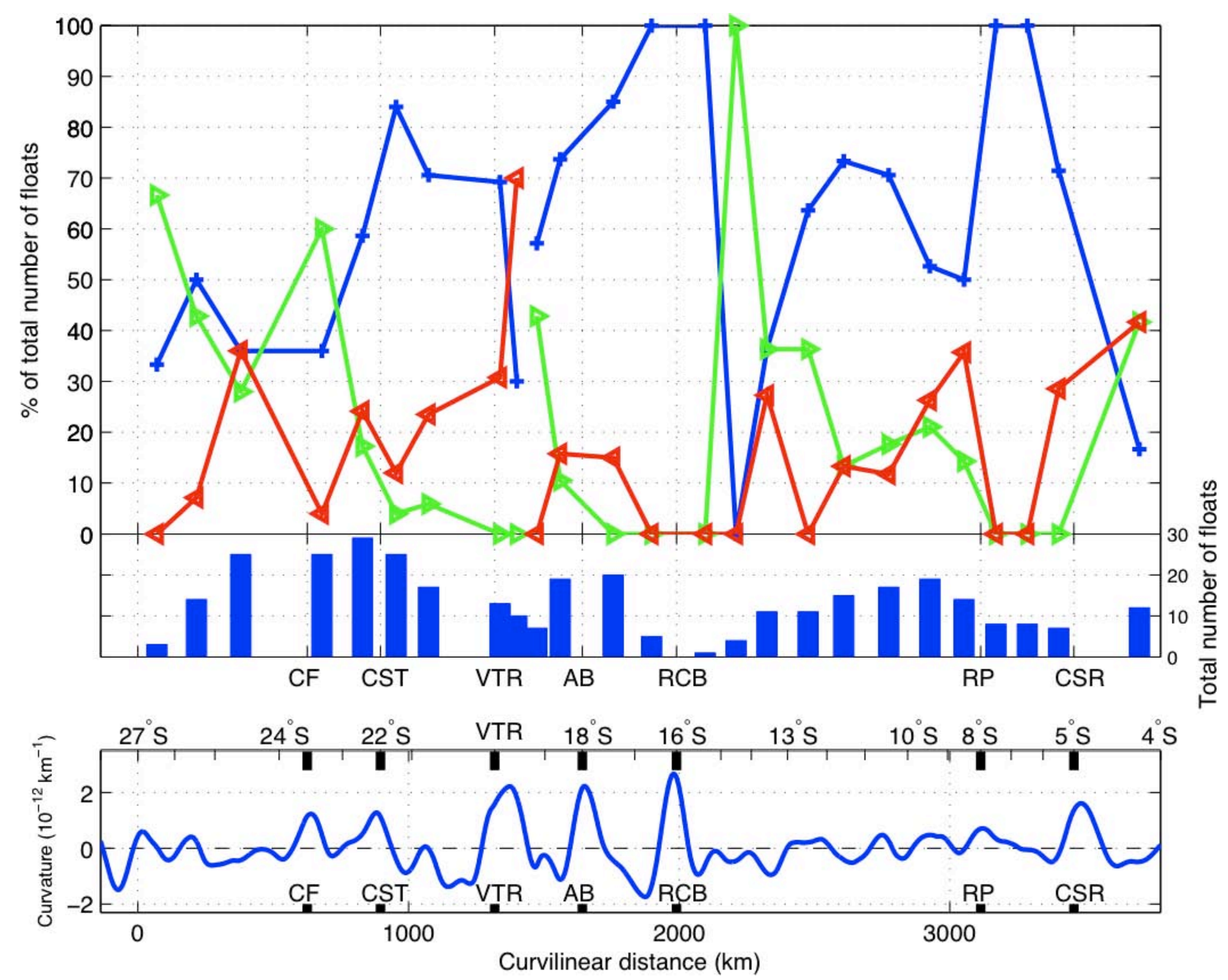

Figure 14: Percentages of float entries in the IWBC (green), float escapes from the IWBC (red), and float along-slope drifts in the boundary flow (blue), as function of curvilinear distance. The fractions are computed in $1^{\circ}$ latitude intervals, except around the inshore passage through VTR. Entries into (and escapes from) the boundary current are defined as the southern (northern) ends of the boundary flow continuous segments shown in Figure 6. Blue vertical bars give the numbers of floats in the $1^{\circ}$ latitude intervals. Latitudinal distribution of the curvature of the smoothed $800 \mathrm{~m}$ isobath is shown at the bottom. Major capes and bathymetric features are: cape Frio $(\mathrm{CF})$, cape São Tomé (CST), Vitoria-Trindade ridge (VTR), Abrolhos Bank (AB), Royal Charlotte bank (RCB), Recife Plateau (RP), and cape São Roque (CSR). 


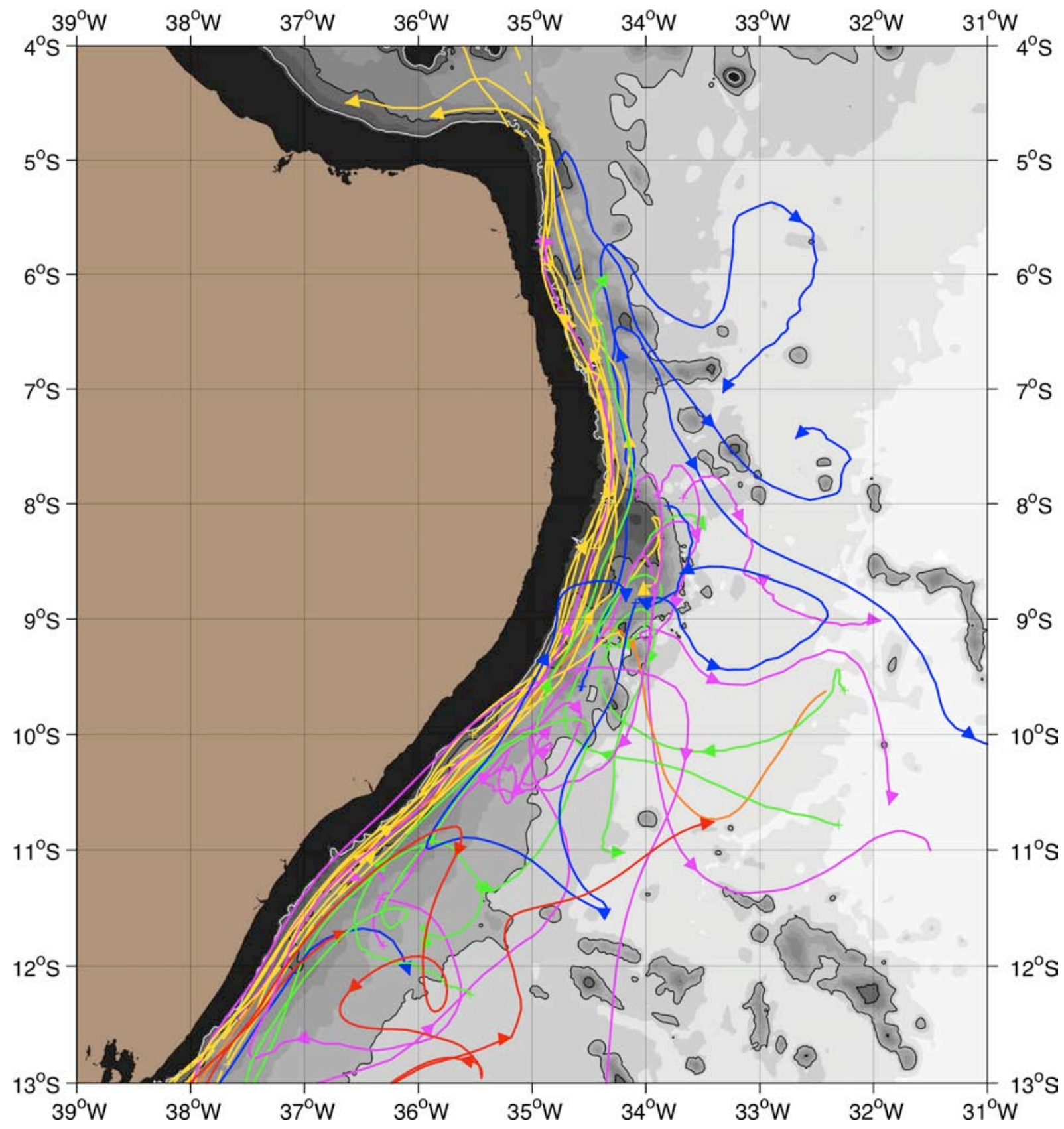

Figure 15: Float trajectories along the continental slope between $13^{\circ} \mathrm{S}$ and $5^{\circ} \mathrm{S}$, illustrating the weak number of entries in the IWBC (green) and large number of exits (other colours) in that region. The yellow trajectories show the floats that remained in the IWBC. One arrow every 30 days. Contoured isobaths are $800 \mathrm{~m}$ (white), $2000 \mathrm{~m}$ and $4000 \mathrm{~m}$. 